\title{
Assessment of residential scale renewable heating solutions with thermal energy storages
}

\author{
Matthias Berger* , Benjamin Schroeteler, Helene Sperle, Patrizia Püntener, Tom Felder, \\ Jörg Worlitschek \\ Competence Centre for Thermal Energy Storage, School of Engineering and Architecture, Lucerne University of Applied Sciences and Arts, Technikumstrasse
} 21, 6048, Horw, Switzerland

\section{A R T I C L E I N F O}

\section{Article history:}

Received 4 August 2021

Received in revised form 29 September 2021

Accepted 11 November 2021

Available online $\mathrm{xxx}$

\section{Keywords:}

Photovoltaic

Renewable energy

Residential

Solar thermal

Techno-economic analysis

Thermal energy storage

\begin{abstract}
A B S T R A C T
Thermal energy storage technologies significantly increase the benefits of decentralized renewable energy production on residential scale. While many studies investigate singular applications of thermal energy storages or provide a broad overview about the current state of research in this field, there is no comprehensive assessment on market-ready solutions. This paper combines a system performance analysis for the combination of photovoltaic and solar thermal generation with storages based on building energy system simulations. Energy systems for single- and multi-family reference buildings with low energy consumption, representing the most common retrofit case in Switzerland, are designed on equal energy performance, and later evaluated for total costs of ownership and financial payback. The results highlight the operational difference in thermal energy storages, where some technologies act more like an energy source in their optimal sizing. Variation of renewable input versus storage size emphasize the individual optimal storage duration. Many solutions are capable of substantially increasing the degree of energy autarky while being competitive without subsidies. This assessment helps guiding future development and design of thermal energy storages.
\end{abstract}

( 2021 The Authors. Published by Elsevier Ltd. This is an open access article under the CC BY-NC-ND license (http://creativecommons.org/licenses/by-nc-nd/4.0/).

\section{Introduction}

Thermal energy storages in the residential sector [1] exist in three basic manifestations: 1) the thermal mass or inertia of a building itself, 2) any kind of buffer storage for hot water, either for space heating ( $\mathrm{SH}$ ) or domestic hot water (DHW), and 3) as dedicated storage unit. The thermal mass is always present as a storage, strongly depending on the chosen construction materials (plywood, bricks, reinforced concrete, glass etc.) and compactness or size [2-4]. The mass can be actively used and operated as a storage, often in conjunction with a remotely switchable heating device $[5,6]$. Storage heaters have been of widespread use during the heydays of nuclear energy and abundant as well as cheap offpeak electricity in many European countries. Heat pumps are a modern-day equivalent, even with the option to contribute to virtual power plants (VPP) and related services [7]. As the second manifestation, many but not all buildings contain one or more

\footnotetext{
* Corresponding author

E-mail address: matthias.berger@hslu.ch (M. Berger).
}

buffer storage for DHW and or SH. Flow-type heaters for DHW or buildings with connection to district heating usually operate without buffer storage. However, if a buffer storage is present, it could be used similar to the thermal mass, operated like a combination of DHW demand (equal to an internal boundary condition) and external services like flexibility to the grid [8]. In the third capacity of a dedicated storage unit, thermal energy storages provide the opportunity to increase the self-consumption of locally produced renewable energy [9]. In this study, we are addressing the thermal energy demand, not the electrical demand. The latter is almost free of direct carbon emissions in Switzerland, while the end-use of thermal energy in the residential sector still has a high share of fossil sources [10].

In Swiss private households, $145 \mathrm{PJ}$ (65\%) of final energy was used for space heating and $32 \mathrm{PJ}(14 \%)$, which is coming from $68 \mathrm{PJ}$ (30\%) oil and $46 \mathrm{PJ}$ (21\%) natural gas [11] in 2018. Note that final energy use and energy demand are not equivalent, since the conversion factors for heating technologies have to be applied [12]. The problem of calculating the technology-neutral heating demand has 


\begin{tabular}{|llll|}
\hline \multicolumn{2}{|l|}{ List of abbreviations } & OPEX & Operational expenses \\
& & PV & Photovoltaic (energy) \\
BES & Battery energy storage & RV & Residual value \\
BTES & Borehole thermal energy storages & SCR & Solar coverage ratio \\
CAPEX & Capital expenses & SFH & Single-family house \\
DHW & Domestic hot water & SH & Space heating \\
ERA & Energy reference area & ST & Solar thermal (energy) \\
ITES & Ice thermal energy storages & SS & Self-sufficiency \\
LCA & Life-cycle-assessment & SWT & Surface water tank \\
LCOE & Levelized cost of energy & TCO & Total cost of ownership \\
MFH & Multi-family house & TES & Thermal energy storage \\
NSTES & Near-surface thermal energy storages & UWT & Underground water tank \\
OC & Own-consumption & VPP & Virtual power plant \\
\end{tabular}

been already derived [12]. The decarbonization of fossil-based $\mathrm{SH}$ and DHW production is practically limited to local photovoltaic electricity production, solar thermal energy, and ambient heat from air- or ground-source heat pumps. All those sources would benefit from a thermal energy storage (TES), which would help dealing with the intermittency and seasonality of solar supply. We do not include system solutions based on electricity from the grid, because all energy scenarios for Switzerland indicate a national shortage of supply. This is due to expiring long-term delivery contracts from France and the phase-out of nuclear power [13], starting with the power plant Mühleberg on December 20, 2019, after 47 years of operation. ${ }^{1}$ Ideally, the heating and cooling sector should be solving its own energy needs without putting additional burdens on the electricity supply. TES enable sectoral coupling and offer potential for a cost-effective and robust solution for decentralized storage capacities, which together provide substantial capacity in the energy system [14,15]. Therefore, we present comparative figures for current market-ready TES technologies and solutions, as a technoeconomic assessment on the residential scale. Two reference buildings, one a single-family and the other a multi-family house, are modeled and simulated in Polysun ${ }^{\mathrm{TM}}$ in 326 different combinations of local renewable energy production and energy storage. The results are compared for energy performance and costs.

This paper is a contribution to and part of the Swiss Competence Center for Energy Research's (SCCER) topical research field of "Heat and Electricity Storage" (HaE). ${ }^{2}$ The SCCERs were granted with funds of more than CHF 100 million for the period 2017-2020 and aiming to find solutions following the government's 2050 Energy Strategy. ${ }^{3}$ Within the HaE work package "Technology Interaction of Storage Systems", the team of authors has been investigating the possible application of different thermal energy storage technologies in the residential sector. While all kinds of energy storages are evaluated in $\mathrm{HaE}$ on four different levels, namely on the technology level, on the energy system level, on the socio-economic level, and based on the assessment of technology demonstrators, our focus in this paper covers thermal energy storages by their technological characteristics, embedded in a system application and analyzed by costs.

\section{Material and methods}

In this chapter we derive the entry point for our investigation (section 2.1), how thermal storages can be modeled for a proper assessment. We compare currently available TES with a detailed description on the methodology for depicting selected systems following (section 2.2). The chapter is concluded by a description of the baseline scenario (chapter 2.3).

\subsection{Thermal storages in energy system models}

There is a long-standing dilemma between the desire to integrate energy storages and renewable energy source into national energy systems and the capabilities of state-of-the-art energy system models to analyze the impact. Engineers and scientists evaluate a broad spectrum of storage technologies [16]. While no single solution fits every purpose, there are many compelling usecases where storage can increase system efficiency, decrease emissions [16] and still be cost-effective [17,18]. Policy makers agree on the potential for storage and their role as a key element for the energy transition stating "that the EU's policies should specifically enhance innovation and the deployment of sustainable energy storage" [19], and that there is a "need for high deployment of storage (6 times today's levels) to deal with variability in the electricity system" [20]. Yet energy system models with the scope of creating scenarios for alternative energy futures on the national or even supra-national scale are usually not capable of evaluating especially thermal energy storages and the related effects of sectoral coupling [21]. System models covering more than one sector, e.g. connecting energy systems with land use and climate change, include the so-called integrated assessment models. They are by definition in terms of scale and granularity limited in the details of technology descriptions as well as spatial and temporal resolution $[22,23]$. In the case of energy system models on the national scale, the level of detail is much better as it can deal with national peculiarities like the presence or absence of certain types of generation (e.g. coal, nuclear, wind) and their specific influences on the electricity grid. There is a broader range of modelling tools available on the national and sub-national scale, often with distinct foci [24]. The review paper by Allegrini et al. shows a variety of different tools and topical packages [24], emphasizing both the reductionistic idea of models being focused and simplistic [25], as well as the missing capabilities. In order to enable energy system models to integrate TES technologies there is a need for a proper system description: What does it mean to add a thermal storage into a given system (in our case on the residential scale)? What would be a proper sizing? What are the related costs?

\footnotetext{
1 https://www.swissinfo.ch/eng/muehleberg-nuclear-plant-_switzerlandproceeds-with-historic-nuclear-shutdown-/45449072.

2 http://www.sccer-hae.ch/.

3 https://www.innosuisse.ch/inno/en/home/thematic-programmes/energyfunding-programme.html.
} 
To fully account for the particularities of thermal storages one has to recognize the difference to storages for electrical energy, e.g. batteries or pumped hydro, for energy system models. We are not referring to dynamic aspects (e.g. grid stability, voltage control) of an electrical power system. In energy system models, the basic parameters for consideration are power and energy, while for specific technologies their maximal value and specific costs are of interest [26,27]. In a simplified fashion, the ease of converting electrical energies to different voltage levels can be modeled by conversion efficiencies [28]. Storage is handled in similar fashion, by relying on roundtrip efficiencies and standby losses. This works for most energy carriers, namely for electricity and chemical energy carriers (e.g. hydrogen, natural gas, etc.), but not for thermal energy. In thermodynamic systems it is not just the quantity of energy which is required for calculation, it is the quality of the energy considered namely the temperature level [21,29]. Consequently, for evaluating TES correctly one needs a model which considers temperature, losses, and the thermodynamics as well as hydraulics of heat conductors, heat exchangers and Carnot heat engines. Our assessment uses the simulation software Polysun ${ }^{\mathrm{TM}}$ by Vela Solaris in the version 11.3. The advantage of a commercial software over a custom and self-made program (e.g. in MATLAB ${ }^{\mathrm{TM}}$ ) is the neutrality towards the scheduling and optimization of different technologies. We hoped to avoid any kind of preference or tailoring towards specific technologies, hence providing a fair comparison with Polysun ${ }^{\mathrm{TM}}$.

\subsection{Selection and sizing of thermal storages}

For running an assessment on TES, the first step is to consider the boundary conditions and select the base case(s) for comparison. In Fig. 1 a), we describe the methodological workflow, which led to the foreseen goal to provide a system performance based on energy and a levelized cost of energy comparison. Three different methodologies have been employed in the process, involving desk research, simulations and assessment.

\subsubsection{Desk research}

In Fig. $1 \mathrm{~b}$ ), the steps based on desk research are highlighted. The residential building sector in Switzerland yields the background of this study which compares solar thermal (ST) and photovoltaic (PV) generation of decentralized and renewable energy with the support of TES. Two scales have been selected, single-family house (SFH) and multi-family house (MFH). Local area grids or district heating grids have not been chosen since their unique size and setup is not favorable for a comparison. It would rather represent the embedding in the surrounding energy system and locally available energy sources not the TES technologies themselves. Details about the reference cases are given in chapter 2.3.

The second point of entry to our study, the selection of technologies, was based on what is currently available on the market. This includes borehole thermal energy storages (BTES), ice thermal energy storages (ITES), surface water tank (SWT), underground water tanks (UWT), near-surface thermal energy storages (NSTES), and battery energy storage as a benchmark (BES, only for PV systems). They are further described in chapter 1.2 of the supplementary material document. We obtained the system specifications in conjunction with the defined system boundaries. This is most relevant for the energy exchange between house and environment, and between some kinds of external storages and the environment (e.g. heat losses through insulation of a NSTES). Furthermore, operating temperatures strongly influence the sizing, efficiency and control paradigms for SH and DHW, and are determined here. Altogether, this provides the background to solicit quotations from vendors. Since costs for labor differ between Switzerland and most other countries, we only asked vendors within Switzerland. Table 1 gives an overview on quotations we collected. The sizing and the cost figures have been compared to literature sources from Switzerland and abroad and if necessary adjusted (e.g. from Refs. [18,30-32]). Many review meetings within the governing
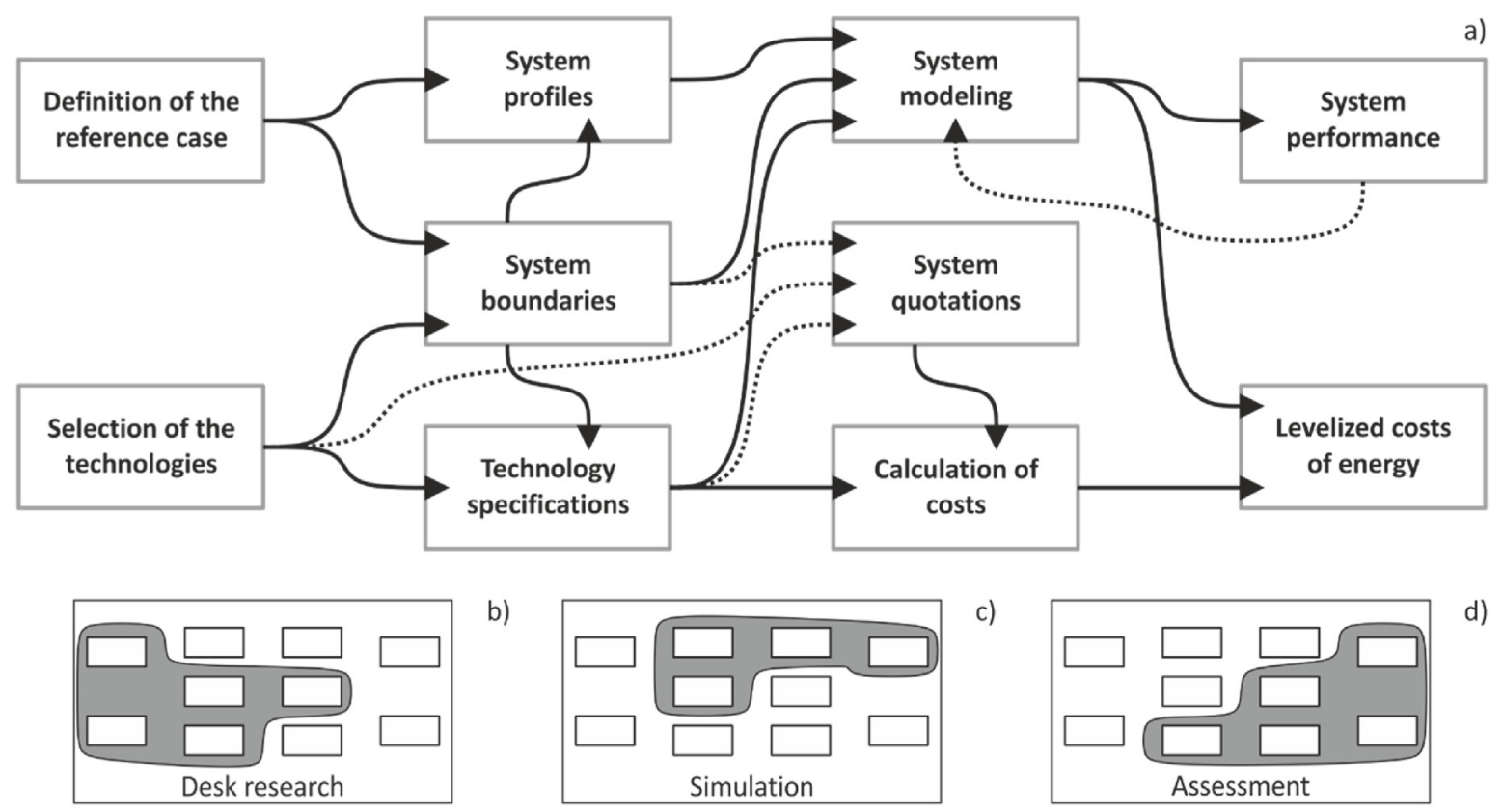

b)

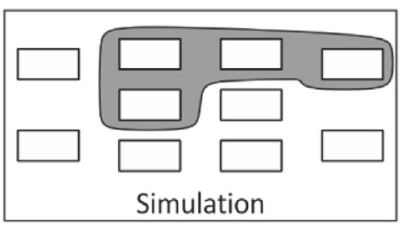

a)

c)

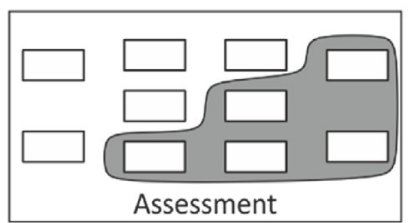

d)

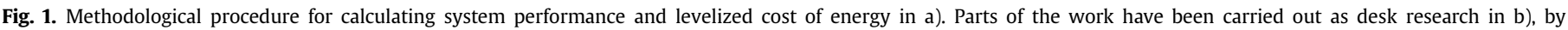
computational simulations in c) and by means of an assessment. 
Table 1

Overview on selected technologies and number of quotations received.

\begin{tabular}{|c|c|c|}
\hline Technology/System & Number of quotations & Comment \\
\hline Solar thermal collectors & 15 & Often includes a broad range of sizes, not only a specific case. \\
\hline Photovoltaic modules & 8 & \\
\hline Heat pumps & 45 & \\
\hline Borehole TES & 16 & Often contains sub-systems (buffer storage tanks, pumps, even ST or PV modules) in the quotations. \\
\hline Ice TES & 5 & $*$ : Only one vendor for the storage itself. \\
\hline Surface TES & 13 & \\
\hline Near-surface TES & $1 *$ & \\
\hline Batteries & 12 & Batteries for home usage on SFH/MFH-scale. \\
\hline Pellet heating & 3 & Additional heating system for solar thermal systems. \\
\hline
\end{tabular}

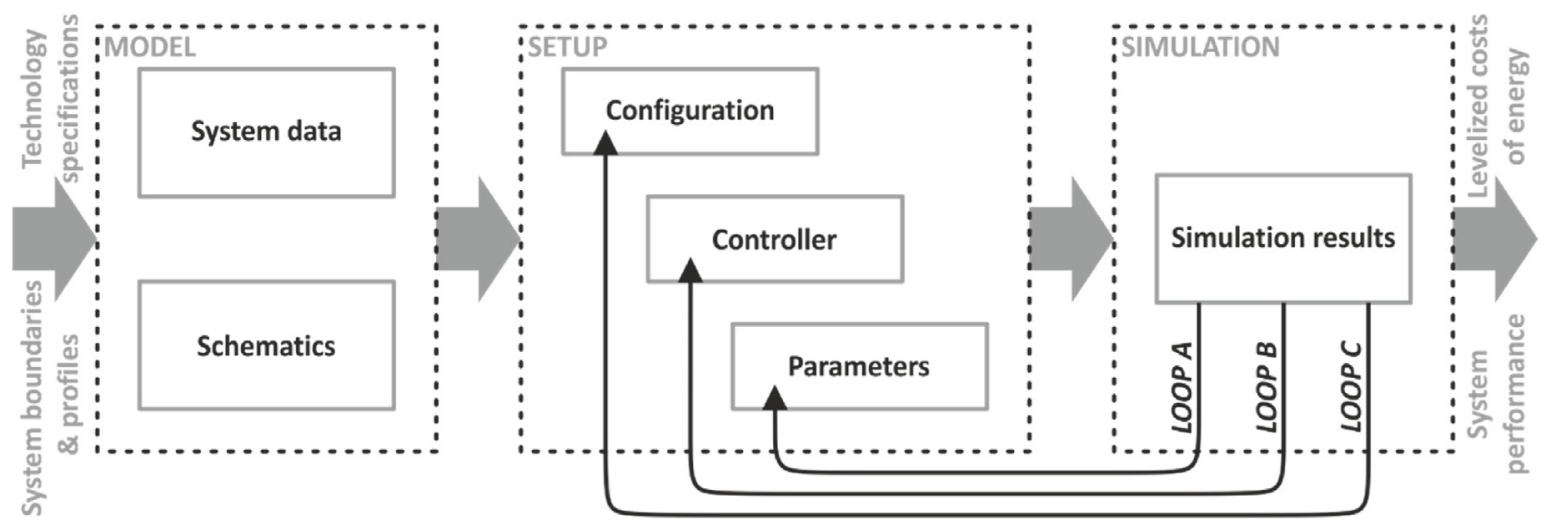

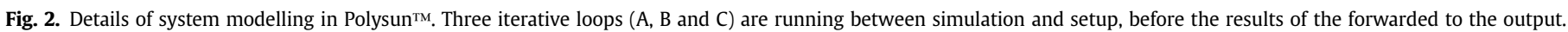

"SCCER Heat and Electricity Storage" framework as well as the standardization efforts inside the scientific community organized by the SCCER Joint Activity Scenarios and Modelling ${ }^{4}$ (JASM) were used to verify and tune the cost data. To our understanding, this is the most comprehensive and real-world data-backed assessment of today, for fair comparison of ST and PV systems with energy storage for residential scale. Studies like Lazard's Levelized Cost of Storage [18] usually do not include such a broad range of thermal energy storage technologies on this scale.

\subsubsection{Simulation}

All simulations have been performed using Polysun ${ }^{\mathrm{TM}}[33,34]$. It offers a rich catalogue on system components (valves, pipes, heat pumps etc.) as well as background data on system boundaries and system profiles (weather data, Swiss building standards etc.).

"The graphical user interface as well as the internal software structure is based on a modular system approach allowing the combination and parameterization of different solar thermal heating systems. Polysun ${ }^{\mathrm{TM}}$ offers reliable yield-forecasts and, in particular, allows comparing different solar systems with one another." [33].

All simulations in Polysun ${ }^{\mathrm{TM}}$ are based on a mix of (internal) catalogue data on components, background data on weather, building specifications as well as $\mathrm{SH}$ and DHW demand. This becomes part of the system model, as shown in Fig. 2. The logical connections between components are drawn and specified in a graphical user interface (GUI) in Fig. 3, whereas the focus is clearly on the thermal side. Only thermal components are interconnected; the electrical part of supply and demand in the model is

\footnotetext{
4 https://sccer-jasm.ch/.
}

incorporated, but not visibly linked. Details to the modeled/simulated systems are included in the supplementary material document. The next step in the model of Fig. 2 is the setup, where the final goal is to run a parameter sweep of PV or ST collectors versus the storage size, indicated as "LOOPA". This might require a manual adaption of the controller in "LOOP $B$ " and consecutively a modification of the configuration as of "LOOP C". By configuration, it is meant, for example, DC-AC converters are chosen from the catalogue by the smallest possible sizing, and the available converters have significant step sizes. The buffer storages for SH and DHW are adjusted in a similar fashion. One could even note a fourth loop, where changes to the controller are used globally throughout all different systems, so that a single technology configuration has not been biased by a "tuned" controller.

\subsubsection{Assessment}

The assessment of renewable heating solutions as sketched in Fig. 1 is carried out for two main criteria, the systems' performance and the levelized cost of energy (LCOE). The calculation of the LCOE is straightforward done by combining the components costs (homogenized and linearized from the quotations) with the results of the parameter sweep of the simulation. In other research studies, run by our group in collaboration with experts in the life-cycleassessment (LCA) domain, we used the LCOE-optimal solutions and took the component data for running an LCA which is not part of this paper. Because solar thermal energy production is included in this assessment and this energy cannot be transferred to the grid like it would be possible with solar photovoltaics, we did not use LCOE for the cost analysis as it is often done [18]. LCOE is given in costs per energy delivered, so we stopped with calculating the costs as total cost of ownership (TCO).

The primary legitimation of our assessment is based on the "neutrality" of Polysun ${ }^{\mathrm{TM}}$ as a comparative energy system modelling and simulation tool. For verification of the results, we 


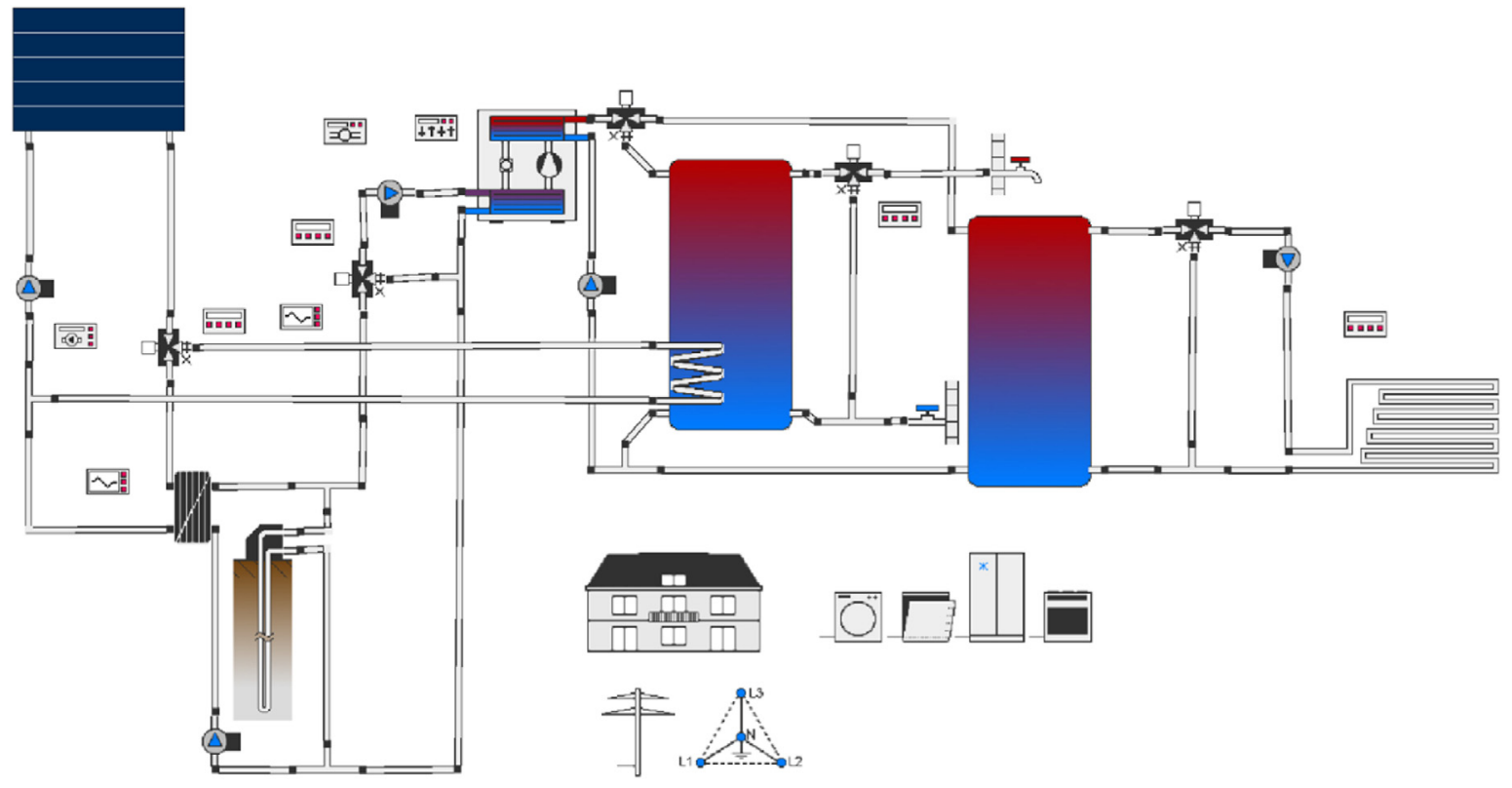

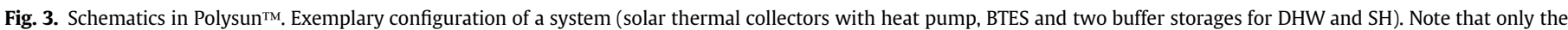

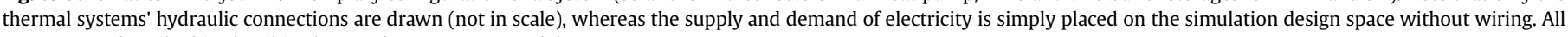
systems are described in detail in the supplementary material document.

compared prices for components within the scientific community, simulation results with literature results and selected systems with real work applications from vendors (by their design and sizing).

\subsection{Reference case, benchmark and demarcation}

The two reference cases for our assessment are buildings virtually located in Berne, Switzerland (lon $7.44^{\circ}$ lat $46.95^{\circ}$ ) at $540 \mathrm{~m}$ (amsl). We simulated one year with reference data from Polysun $^{\mathrm{TM}}$. The buildings are assumed to be a renovation of existing buildings based on a "Minergie-A" low-energy house [35,36]. The building standard for "Minergie- $\mathrm{A}^{\text {" }}$ is a net energy demand of less than $60 \mathrm{kWh} / \mathrm{m}^{2}$ per year (for renovation). One building is a SFH of $140 \mathrm{~m}^{2}$ energy reference area (ERA) and the other a MFH of $1500 \mathrm{~m}^{2}$ ERA. In both cases, we chose the indoor set temperature at $21^{\circ} \mathrm{C}$ at daytime and $20{ }^{\circ} \mathrm{C}$ at nighttime and considered a ground floor heating system with $35^{\circ} \mathrm{C}$ inlet temperature and $28^{\circ} \mathrm{C}$ return. This choice has a severe impact on the later simulations [23]. For DHW, we took a profile with $200 \mathrm{~L} / \mathrm{d}$ at $50{ }^{\circ} \mathrm{C}(\approx 3419 \mathrm{kWh}$ p.a.) for the SFH and $1562 \mathrm{~L} / \mathrm{d}(\approx 25,917 \mathrm{kWh}$ p.a.) for the MFH. The space heating demand is not given a priori; the building standard is fulfilled by setting the thermal transmission coefficient of the walls (U-value) to $25 \mathrm{~W} / \mathrm{K} \cdot \mathrm{m}^{2}$ The SH demand is furthermore influenced by multiple losses between generation, distribution and storage of heat. Polysun ${ }^{\mathrm{TM}}$ calculates detailed losses across system boundaries, especially for all kinds of underground storages (BTES etc.). We took into account the long-term thermal stability of the soil and calculated 50 years beyond the reference year, so that no undesired temperature drop or freezing in the ground occurs, similar to the standard SIA 386/4 on borehole heat exchangers [revision forthcoming]. In general, there exists a practical gap between building standard and real energy consumption, known as energy performance gap [37,38]. All this has been contemplated for system design and consecutive simulations.

\section{Results}

We ran thousands of simulations in Polysun ${ }^{\mathrm{TM}}$, triggered by changes due to previous results as described with the iterative loops in Fig. 2. The focus has been a parameter sweep of different numbers of PV or ST modules against the respective storage sizes. While storage sizes have been defined with discrete steps, according to the quotations, the number of rooftop-mounted modules could range from one to any integer. In the following plots, we show only selected integers, of which the upper number may even exceed the available roof surface. For ST, we chose half a modules size in case of the SFH for illustration of scaling purpose only. The combination of PV without storage, with batteries and with TES is shown for SFH and MFH with 200 simulations in total. The combinations of ST with storage have less options, therefore we ended up with 30 simulations for SFH and 55 for MFH. We decided to exclude ice storage from the following comparison, as it would require a cooling demand to fully utilize the exergy benefits of the low storage temperature. Since cooling demand is not modeled in this assessment, results of ice storage systems would have been misleading in comparison.

The results chapter is continued in the supplementary material document, where the temporal behavior, the energy flows as Sankey diagrams, and detailed results of chapter 3.1 as tables can be found.

\subsection{Variation of renewable production versus storage size}

In the end, there are a total of 326 simulations shown in the Figs. 4-9. To ease the comparison, we kept a constant scale within groups of cases, resulting in four groups (SFH $+\mathrm{PV}, \mathrm{MFH}+\mathrm{PV}$, $\mathrm{SFH}+\mathrm{ST}$, and MFH $+\mathrm{ST}$ ). The primary question is: Does a system with a given technology investment beyond the basic retrofit case pay off? This is answered by using relative total cost of ownership. If the value for $T C O_{S O L} / T C O_{R E F}$ is below "1", it does. The secondary 


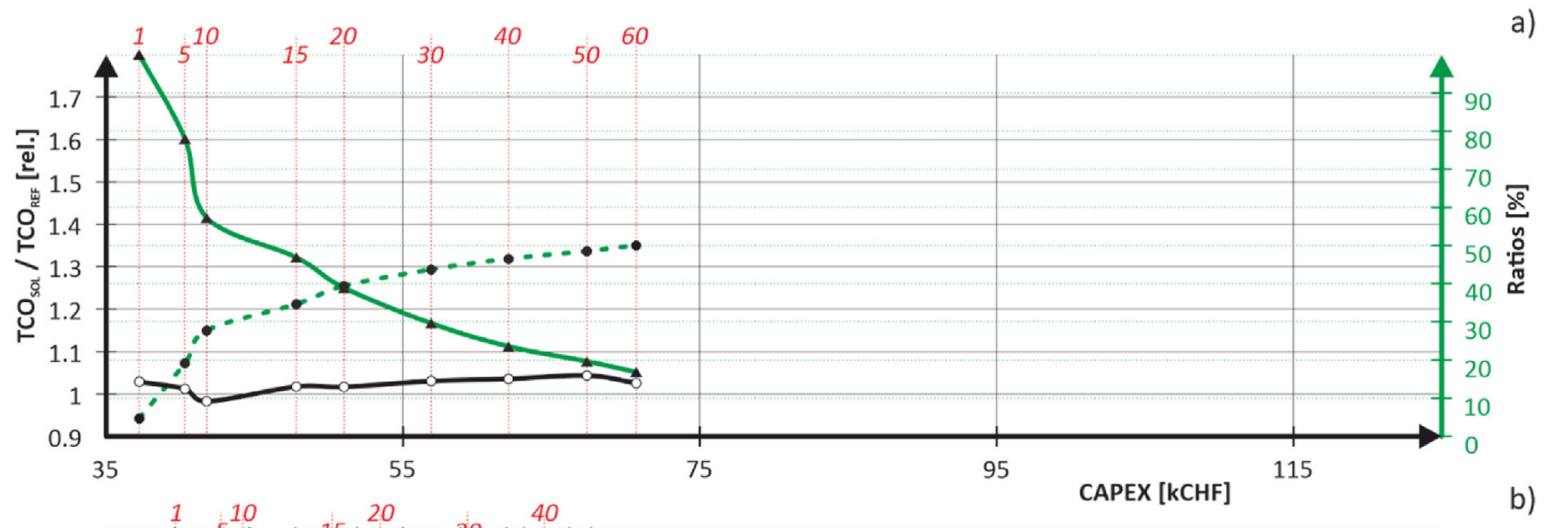

a)

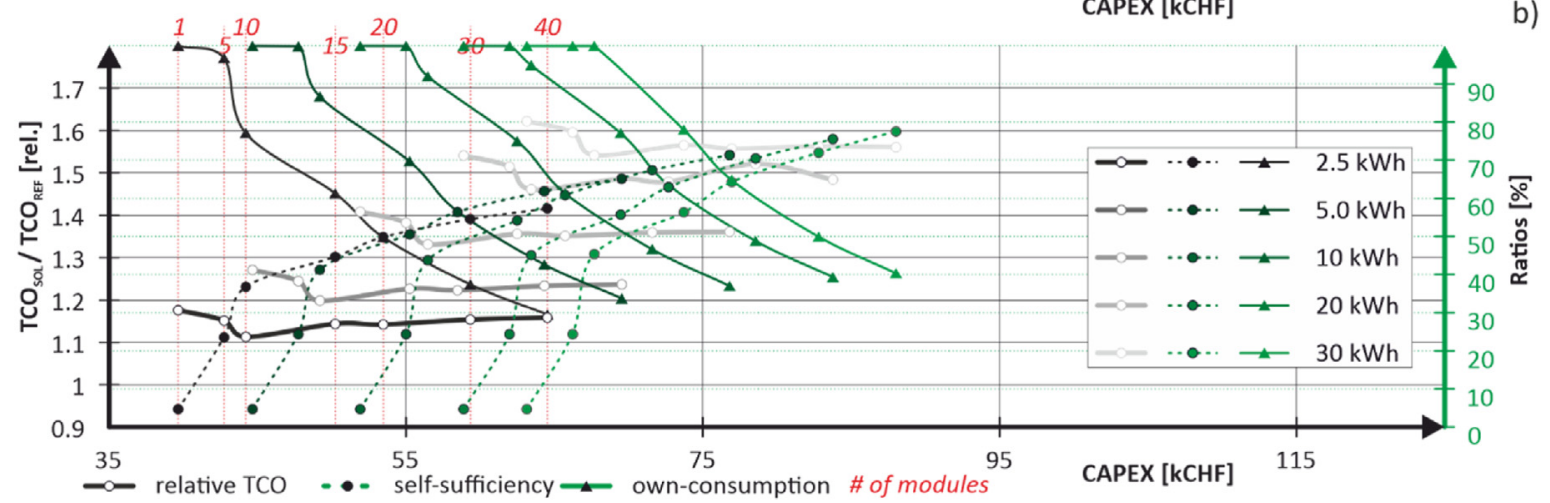

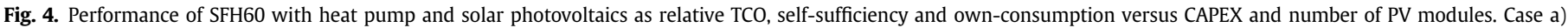
represents PV-only, case b) has a variation of battery sizes in addition (see legend in the graph with battery capacity).

question follows: How does a given technology scale by numbers of modules (PV or ST) as well as size of storage, with respect to CAPEX, self-sufficiency, own-consumption, and solar coverage ratio? Note that in all cases with a variation of storage sizes, we did indicate the number of modules in red only for the smallest size. Relative TCO is always given in black solid lines (or shades of gray for variation of storages sizes), SS and SCR in green dashed lines (or shades of green for variations) and $O C$ in solid green lines (or shades of green for variations).

For all PV-only variations on the SFH level, see Fig. 4 a), the $\mathrm{TCO}_{\text {SOL }} / \mathrm{TCO}_{\mathrm{REF}}$ value fluctuates at around 1 . The cost optimum is reached with 10 PV panels at a TCO of CHF 152'614 compared to the reference system with a TCO of CHF 155'342. This variation reaches an own-consumption ratio of $57 \%$ and a self-sufficiency of $28 \%$. The maximum achievable SS ratio for the reference building with PVonly reaches $46 \%$ (40 panels) with a TCO of CHF $160^{\prime} 866$. Note that the case of 50 and 60 panels has been included for extrapolation, however, it exceeds the available roof surface. The in general small fluctuations in the TCO ratio can be attributed to the revenue from the feed-in tariff. Higher investment costs are compensated by higher feed-in revenues. This effect becomes dominant with large numbers of panels, hence the dip in relative TCO for 60 panels.

In contrast, the PV systems with batteries in Fig. 4 b) show a significantly broader cost range, with all variations being more expensive than the reference system with relative TCO ratios ranging from 1.2 to 1.6 . The degree of self-sufficiency is significantly increased by adding a BES, but to a lesser extent by the size of the battery. The variation with $30 \mathrm{PV}$ panels and the smallest simulated battery capacity of $2.5 \mathrm{kWh}$ reaches a SS of $55 \%$ and OC of $37.5 \%$ (TCO: CHF 179'423 CHF). Compared to this, the largest system for the reference building with $40 \mathrm{PV}$ panels and a battery capacity of $30 \mathrm{kWh}$ reaches a SS ratio of $78 \%$ and OC of $40.4 \%$ (TCO: $242^{\prime} 303$ $\mathrm{CHF}$ ). Consequently, under the current cost situation, an ordinary
PV system is more cost-efficient than a PV system with battery. The significant increase in self-sufficiency through BES comes along with much higher total costs of ownership, therefore a small battery with about $1 \mathrm{~h}$ of PV peak production is best. For comparably large BES at maximum PV size the gain in SS is overshadowed by a low $\mathrm{OC}$, which is rising below average.

In the case of a) NSTES and c) BTES systems of Fig. 5, only one storage size has been simulated each $\left(150 \mathrm{~m}^{3}\right.$ and $180 \mathrm{~m}$, respectively). The chosen NSTES storage size is given by the available option on the market for single family houses. The BTES is acting not exactly as a storage; rather it is a heat source, which must be partially regenerated according to environmental protection standards. The length of the borehole is proportional to the maximum power to be extracted and determined by the soil type (reference location: humid clay). A new version of the respective standard on BTES and regeneration is currently in preparation (SIA 384/6). The TCO ratio for NSTES lies between 1.54 and 1.60 , whereas the TCO ratio of BTES is slightly lower with $1.43-1.50$. Both systems show similar TCO and self-sufficiency behavior. With 20 PV panels, a SS ratio of above $50 \%$ is reached. Scaling up the number of PV panels from 20 to 40 panels results in a SS ratio of over 65\% with slightly higher CAPEX and TCO. Thus, these two systems are in a similar cost range as a large PV battery system ( $30 \mathrm{kWh}$ ), although the latter achieves even higher self-sufficiency. PV-SWT systems in Fig. 5 b) are less expensive than NSTES and BTES systems with TCO ratios between 1.14 and 1.30 . The smallest variant starts with CAPEX of CHF 37'213, compared to the reference system with CHF $32^{\prime} 052$. To reach a SS above $50 \%$, the number of panels must be increased to the maximum. This is due to higher losses of surface water tanks compared to underground storages. BTES, in comparison, are gaining significant amounts of heat from the environment, and the NSTES can lose and gain heat from the surrounding soil. In the discussion we are looking more into those aspects. The decisive 


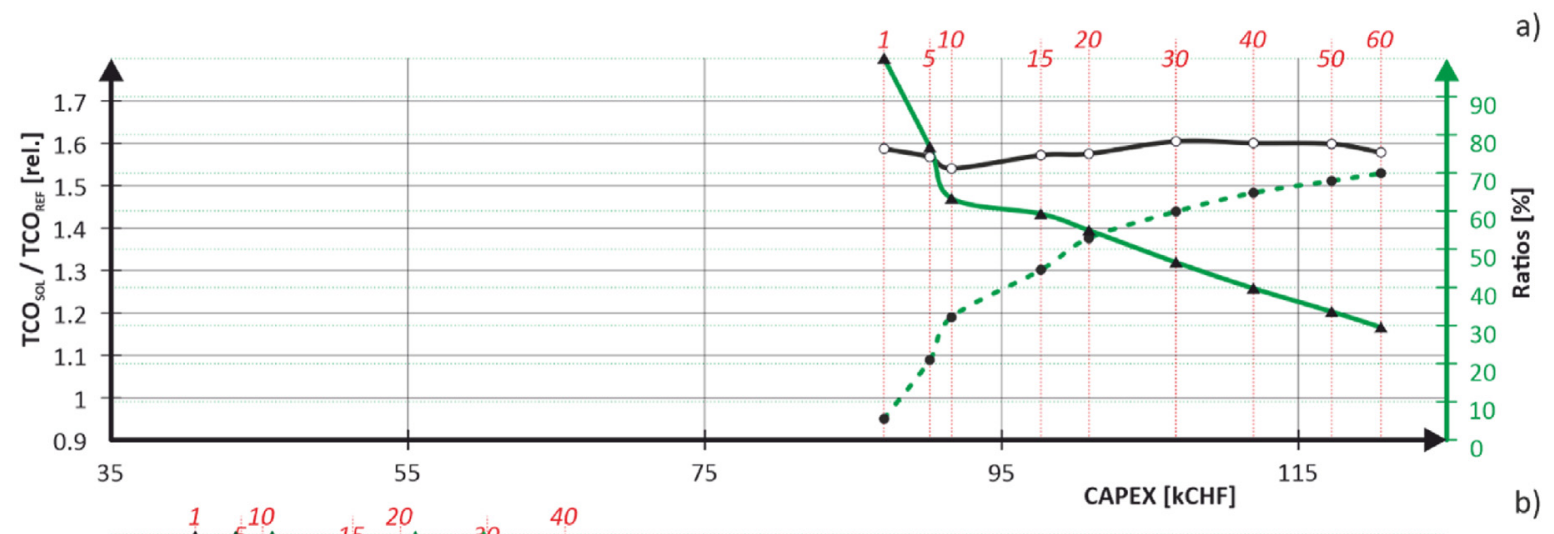

a)

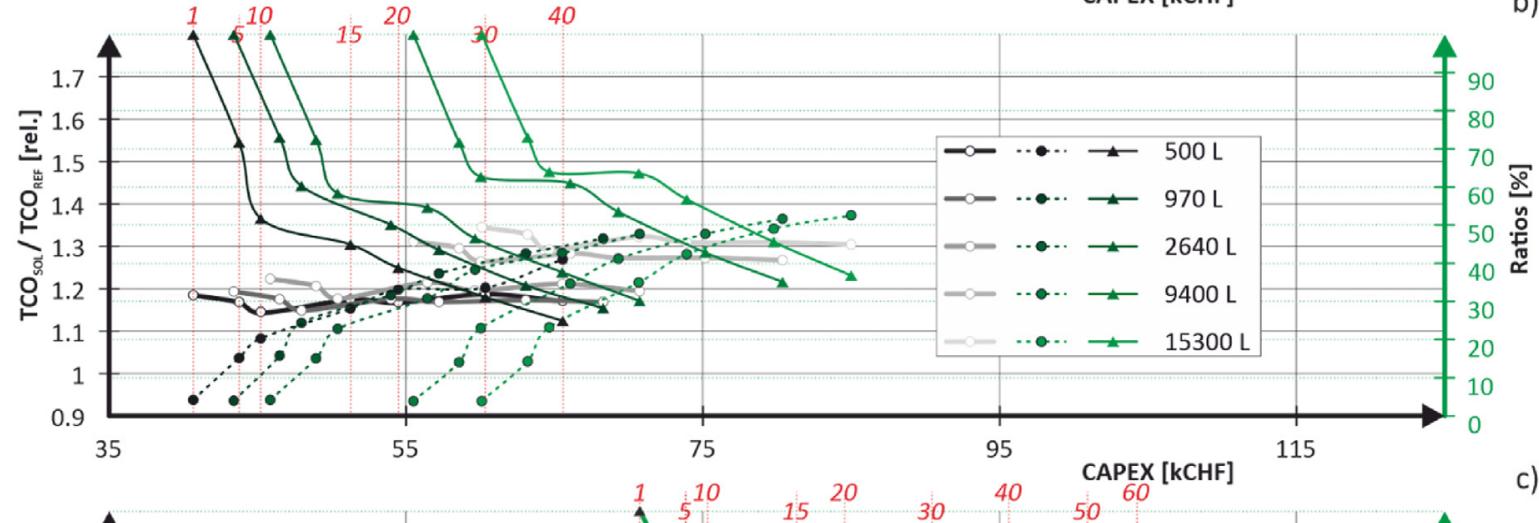

)

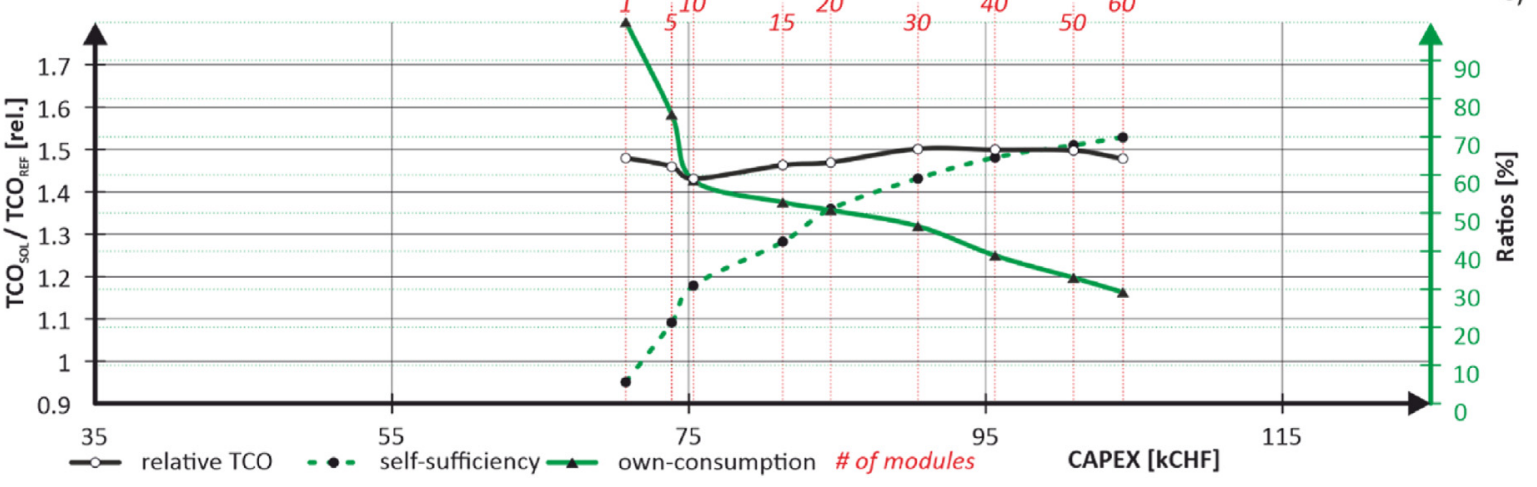

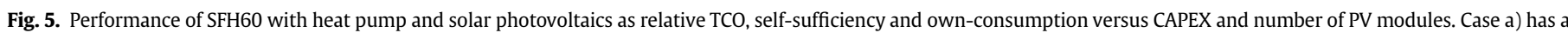
NSTES, case b) has a variation of SWT sizes, and c) has a BTES.

factor for the increase of SS is rather the enlargement of the PV area than the size of the storage tank. Regarding the OC ratio of PV systems, it becomes clear that all investigated storage technologies can increase the OC ratio by up $40 \%$. This is most obvious with the battery storage (Fig. 4). With an increase in installed PV power, the OC ratio decreases since more surplus is produced than can be taken up by demand and storage.

Looking at the lower relative TCOs on MFH-level in Fig. 6, all systems are more cost efficient than on SFH-level. The relative TCOs further decrease with the number of PV panels. The cost optimum is always found at the maximum PV area with 230 PV panels for the reference building. This shows that PV systems on the MFH level are much more profitable than on the SFH level. PV-only systems are always less expensive than the MFH reference system, see Fig. 6 a). Battery systems with $40-50 \mathrm{kWh}$ are also more favorable than the reference system (TCO ratio $<1$ ). Systems with larger battery capacities can be more profitable than the reference system if the PV area is large enough, as in Fig. 6 b). The largest battery capacity of $200 \mathrm{kWh}$ can achieve a self-sufficiency of just over $50 \%$.

A major difference to the SFH-case of Fig. 5 is visible in Fig. 7 for the MFH-case. In terms of the NSTES systems in Fig. 7 a), simulations show that the energy demand could be best covered with the $900 \mathrm{~m}^{3}$ and $2250 \mathrm{~m}^{3}$ storage variant. The less expensive storage with $450 \mathrm{~m}^{3}$ is therefore not suited for the reference building in combination with PV. In contrast, the $2250 \mathrm{~m}^{3}$ can hardly achieve higher degrees of self-sufficiency than the $900 \mathrm{~m}^{3}$ variations, instead has significantly higher TCO and CAPEX. A variation with $230 \mathrm{PV}$ panels and $900 \mathrm{~m}^{3}$ storage is about $10 \%$ more expensive than the reference systems and reaches a SS of $46 \%$ with an OC of 55\%. In comparison, PV BTES systems are less expensive than the reference system with a correspondingly large PV surface, see Fig. 7 c). The extension of the borehole length has only a minor influence on the TCO compared to other storage systems. The energy demand is covered with borehole lengths of 900-1800 m. With $230 \mathrm{PV}$ panels and $900 \mathrm{~m}$ borehole length (TCO ratio: 0.89) a SS of $45 \%$ and OC of $55 \%$ can be achieved. PV SWT systems in Fig. 7 b) also perform 


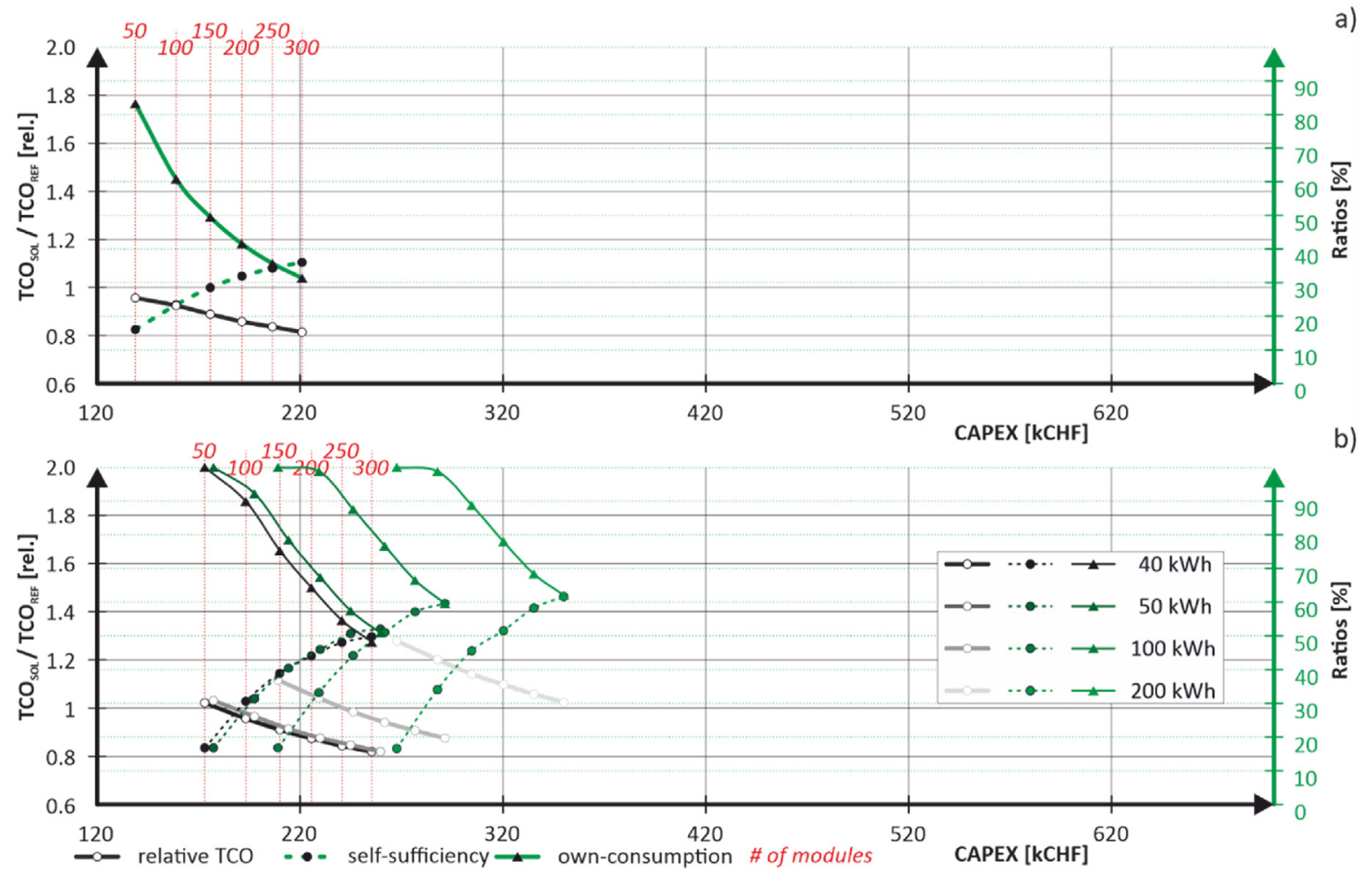

a)

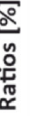

)

Fig. 6. Performance of MFH60 with heat pump and solar photovoltaics
represents PV-only, case b) has a variation of battery sizes in addition.

much better than the reference system. Larger tanks have higher TCOs than smaller tanks and the gains in self-sufficiency are minimal, so that smaller tanks are preferable.

For all PV MFH storage systems, the optimal cost is achieved with the largest possible PV area combined with the smallest evaluated storage capacity. Thereby SS ratios of more than $40 \%$ can be achieved.

Note that for all ST TES combinations the solar coverage ratio has been calculated; this excludes the household electricity demand but matches the intended use-case of ST installations. The simulated ST storage systems on SFH level in Fig. 8 do not reach a TCO ratio below 1, as in the case of SFH PV storage systems. ST SWT systems in Fig. 8 b) with moderately large thermal energy storages prove to be the most cost-effective solutions, with TCO ratios of more than 1.3. The leap in costs for systems with a thermal energy storage volume of $31,900 \mathrm{~L}$ is striking: massively higher costs with moderate gains in SCR compared to smaller tanks. In contrast, the pellet consumption decreases to keep such a large volume of water at a constant high temperature during the winter months. The losses to the environment cannot be completely compensated by the tank insulation. Tank volumes of 2640 L already achieve a SCR of over $50 \%$ with the corresponding solar surface. CAPEX starts at around CHF $50^{\prime} 000$, which is significantly higher than for the reference system with CHF $33^{\prime} 052$. This is mainly due to the high investment costs for the pellet heating system and the thermal energy storage. NSTES and BTES systems in Fig. 8 a) and c), respectively, require relatively high investments and have a TCO ratio above 1.4. In contrast to the SWT, however, quite high SCR of around $90 \%$ values can be achieved. In both systems the SCR reaches almost a saturation at around $90 \%$ with 6 solar collectors.
Beyond that, more solar collectors cannot achieve significantly higher SCRs.

On MFH-level, as in Fig. 9, all solar thermal storage systems prove to be more cost-effective than on SFH level. However, all MFH ST variations have a TCO ratio above 1, except for a), for the smallest NSTES with $450 \mathrm{~m}^{3}$. Despite this promising result, there is a gap in the energy balance, which means that the heating demand is not covered. For NSTES with small number of modules and corresponding storage, the regeneration by ST is insufficient and the ground cools below an acceptable threshold (for \# ST 1, 5 \& 10 @ $450 \mathrm{~m}^{3}$; \# ST 1 \& 5 @ $900 \mathrm{~m}^{3}$; \# ST $1 @ 2250 \mathrm{~m}^{3}$ ). Those solutions would require an additional heat source, which is not foreseen in the system. Consequently, those solutions are invalid.

A general observation is the influence of ST size on costs. The smaller the solar thermal area is, the closer the TCO is to the reference system. This behavior contrasts with MFH PV systems, which become more favorable as the PV area increases. The TCO range for all systems is very wide, from just over 1 to above 2 . NSTES systems show the highest possible TCO range. This is largely due to the high cost of excavation, which is also associated with high uncertainty at this scale. The CAPEX range is also very broad starting from just above CHF $60^{\prime} 000$ for SWT systems to CHF $760^{\prime} 000$. In comparison, the CAPEX of the reference system is CHF $103^{\prime} 427$. In terms of SCR, NSTES and BTES systems can reach high ratios of over $80 \%$ even with smaller storage capacities. With a collector number of 5 or more, the SCR for these systems increases significantly. With SWT systems, the SCR increase is considerably flatter. To achieve a SCR of over $50 \%$, a relatively large collector area and storage tank of at least $30^{\prime} 000 \mathrm{~L}$ has to be installed, since the heat losses are greater than with underground storages. 


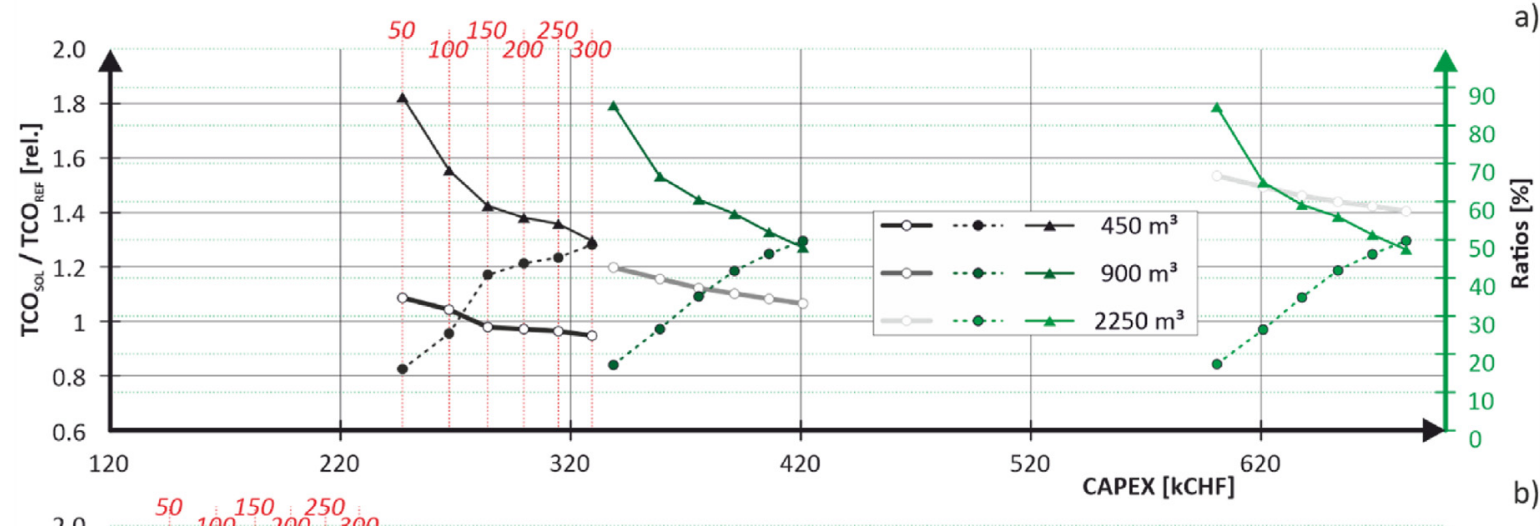

a)

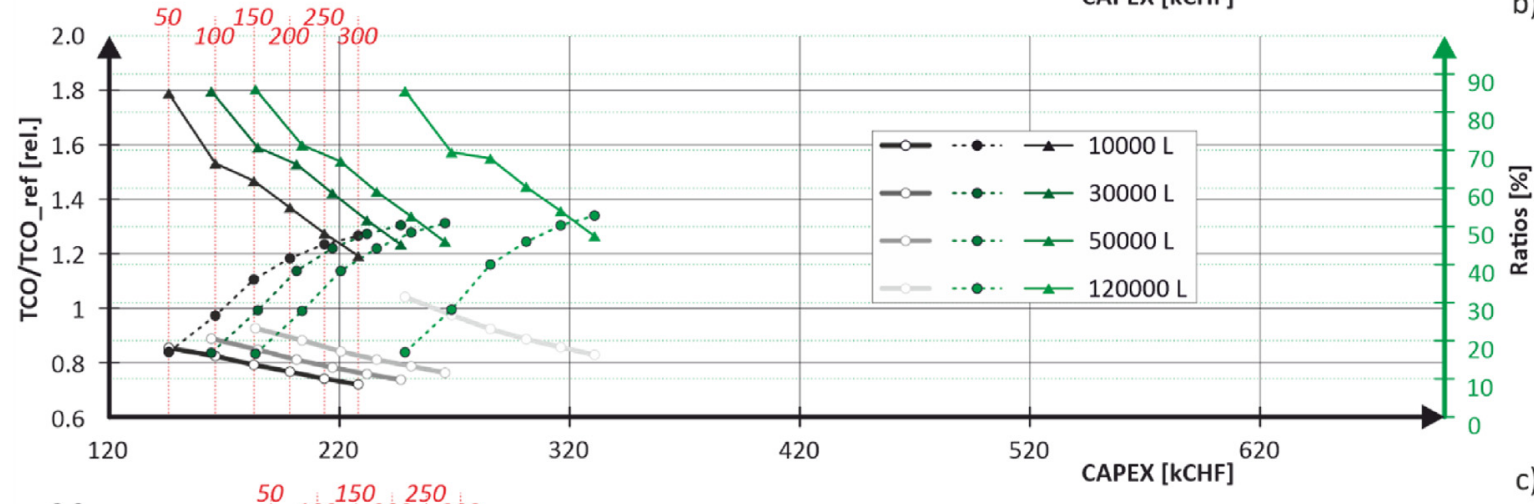

)

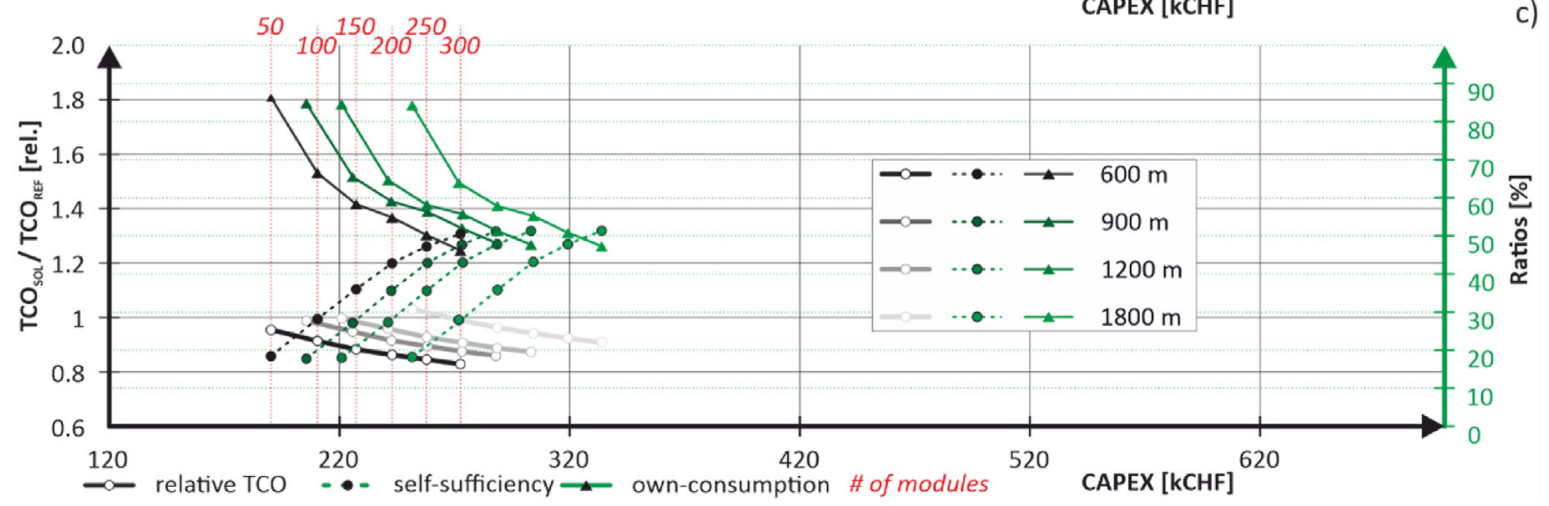

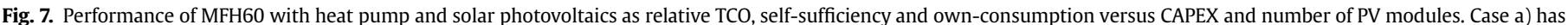
a NSTES, case b) has a variation of SWT sizes, and c) has a BTES.

\section{Discussion}

Providing a fair comparison of storage technologies for renewable heating on SFH and MFH scale has certain limits. Everything is strongly depending on the given starting point of the assessment, e.g. the choice of the SH consumption (corresponding to an isolation level), the location (with the climatic reference), and the settings for indoor temperature [23]. Furthermore, the kind of services provided are determining the potential for the different systems. We did not consider space cooling, which would benefit all TES with regeneration. The so-called free cooling [39], or geo-cooling in the case of BTES, where diurnal difference in the ambient temperature are used for space cooling, can be coupled with TES in many ways [40]. This would totally alter the system designs of chapter 1 in the supplementary materials document and the results provided in chapter 3. Again, we have to emphasize the fact that the assessment presented in this paper is only valid with the given settings and boundary conditions. To our best knowledge, what we did show was the most relevant case in Switzerland (SFH/MFH with $<60 \mathrm{kWh} / \mathrm{m}^{2}$ and year), as this is the target building stock for retrofit [41,42].

Since retrofit is primarily an investment, and only in a secondary regard an opportunity to reduce energy consumption, GHG emissions and environmental impact, the key questions becomes: How long does it take for a certain technology in the respective optimal configuration of storage, renewable supply and auxiliary equipment (heat pump, valves, buffer storage etc.) to reach break-even? We did answer the previous questions from chapter 3 ("Does a system with a given technology and investment -beyond the basic retrofit case-pay off?") with a "partially yes", there are many systems which do pay off and all benefit from a maximized ST or PV production in combination with a small storage ("How does a given technology scale ... ?"). The length of time for investment decisions to break-even is given by the differences in the trajectory of total costs of ownership. Assuming the discounting is constant over time, linear equations for the TCO of the reference case $T C O_{R E F}$ (see 


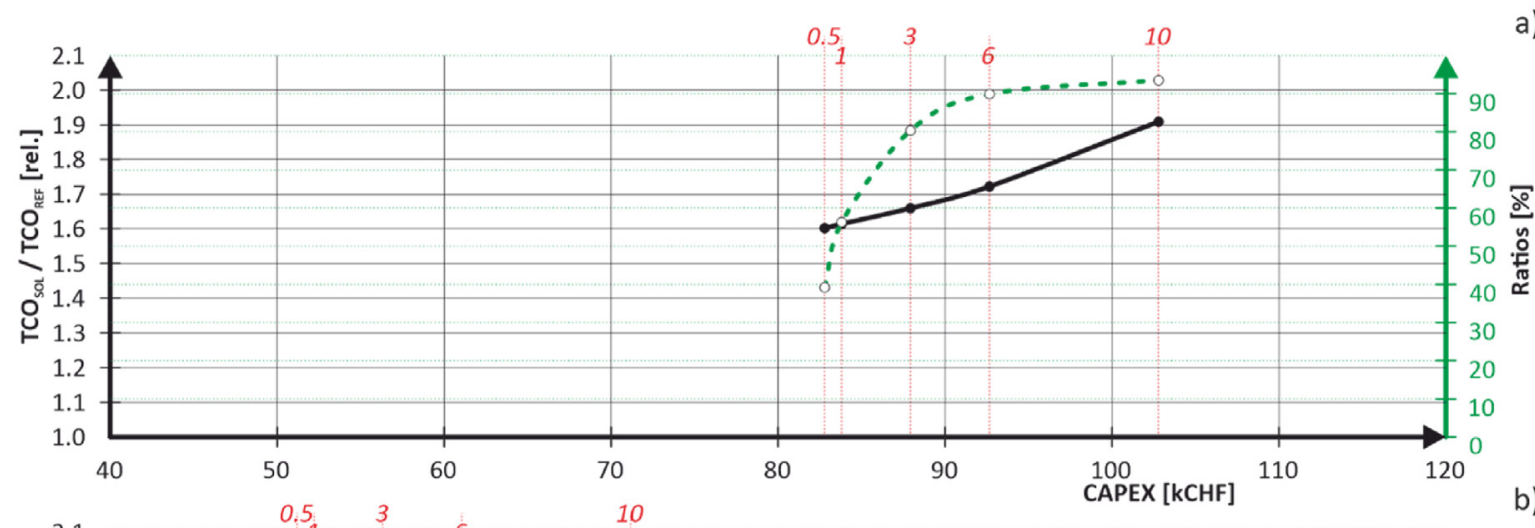

a)
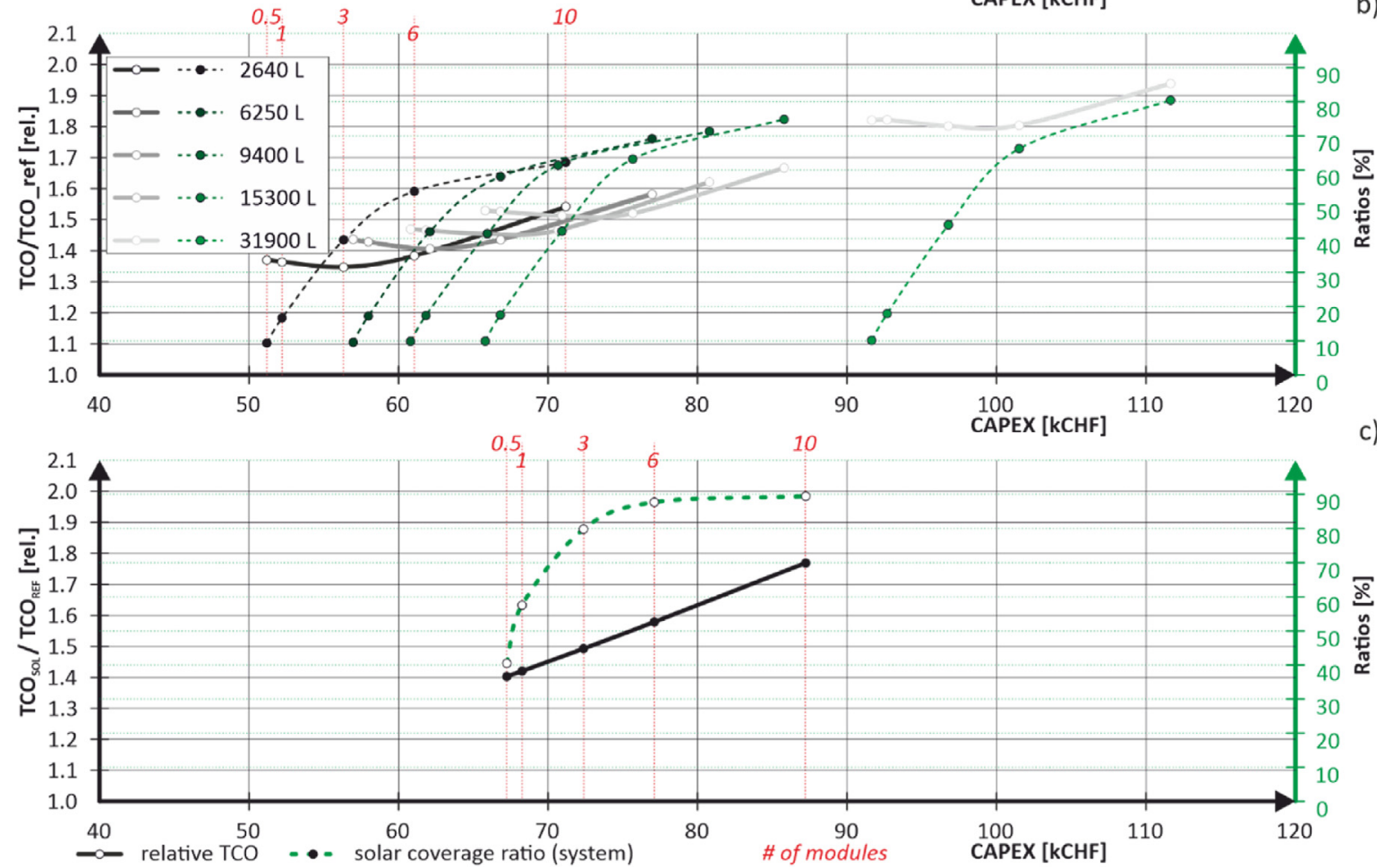

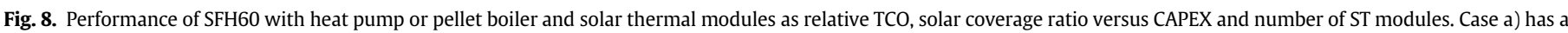
NSTES, case b) has a variation of SWT sizes, and c) has a BTES.

Fig. 3, basic retrofit with a heat pump as investment) and of the solution $\mathrm{TCO}_{S O L}$ (to which it is compared) will occur as shown in Fig. 10.

If a relative TCO of Eq. (5) in the supplementary materials document is below 1, the number of years to reach break-even is finite. This can be calculated based on finding the intersection in Eq. (1) and the linear equations for the TCO in Eq. (2),

$\mathrm{TCO}_{\mathrm{REF}}=\mathrm{TCO}_{\mathrm{SOL}}$

$T C O(t)=C A P E X+O P E X / n \cdot t-R V$

which can be resolved and transposed for the time $t$ in Eq. (3), where $n$ of 50 years is the systems lifetime the TCO are annualized against.
$C A P E X_{R E F}-R V_{R E F}+O P E X_{R E F / n} \cdot t=C A P E X_{S O L}-R V_{S O L}+O P E X_{S O L} / n \cdot t$ $\frac{\left(O P E X_{R E F}-O P E X_{S O L}\right)}{n} \cdot t=\left(C A P E X_{S O L}-R V_{S O L}\right)-\left(C A P E X_{R E F}-R V_{R E F}\right)$ $t=\frac{\left(C A P E X_{S O L}-R V_{S O L}\right)-\left(C A P E X_{R E F}-R V_{R E F}\right)}{\left(O P E X_{R E F}-O P E X_{S O L}\right)} \cdot n$

$t=\frac{\left(R V_{R E F}-R V_{S O L}\right)-\left(C A P E X_{R E F}-C A P E X_{S O L}\right)}{\left(O P E X_{R E F}-O P E X_{S O L}\right)} \cdot n$

There are four different kinds of solutions for Eq. (4) feasible. For $\mathrm{t} \leq 50$ years, the solution does pay off compared to the reference case within the systems lifetime. For $t>50$ years, the solution would pay off in far future, but it is not economic within the lifetime. There might be a theoretical case where the slope of both lines is equal, both are in parallel with $\triangle O P E X_{S O L} / \Delta t=$ 


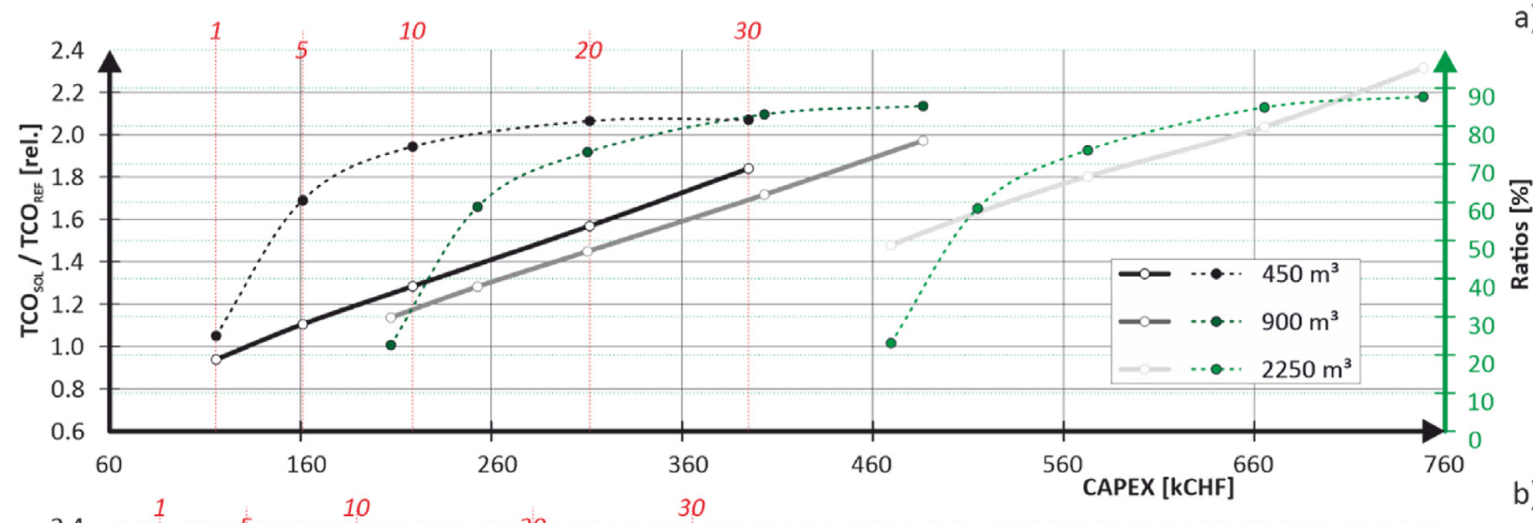

a)

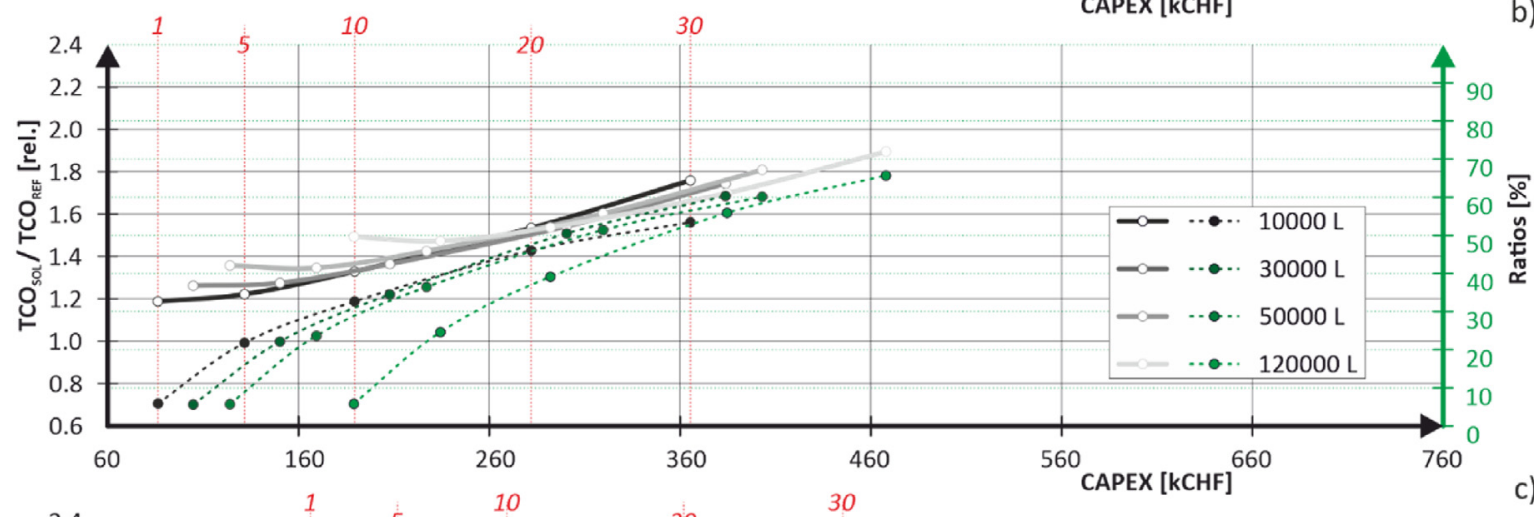

)

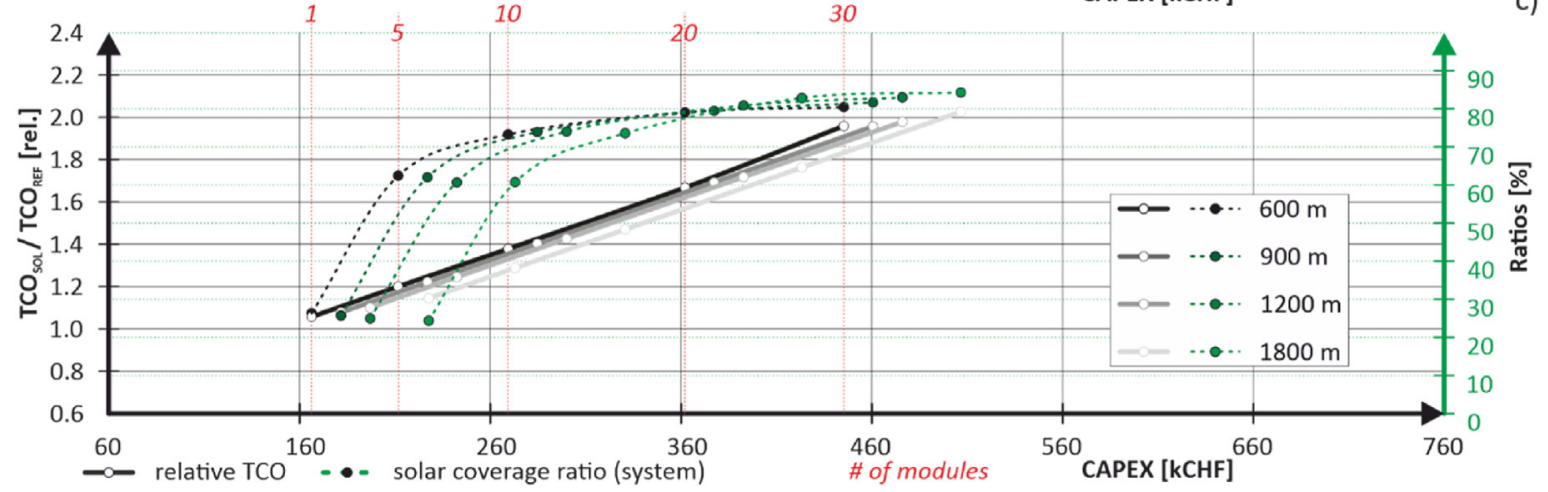

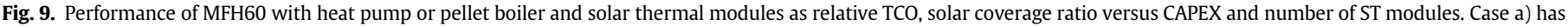
a NSTES, case b) has a variation of SWT sizes, and c) has a BTES.

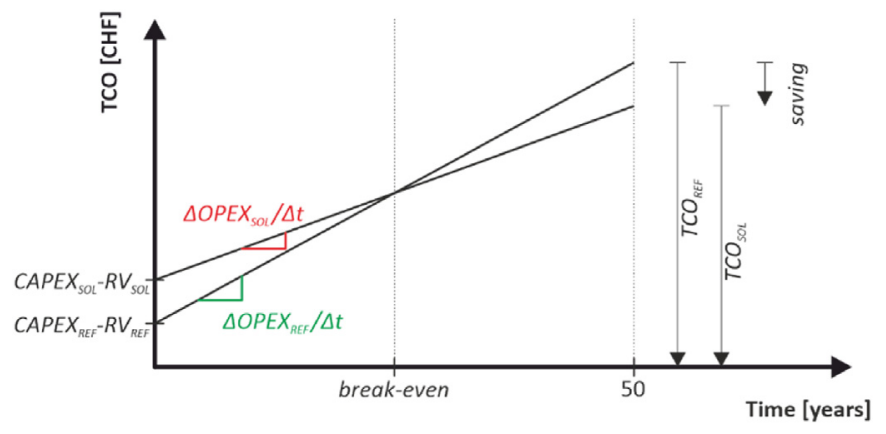

Fig. 10. Amortization of additional investment of a system solution (sol) with lower OPEX compared to the reference system (ref) yielding break-even and savings.

$\triangle O P E X_{R E F} / \Delta t$. Here there is no return of invest either. The fourth case is when t becomes negative (rel. TCO $>1$ ) and the line intersect "in the past".

The break-even values for all systems of $t \leq 50$ years are shown in Fig. 11. All sets of curves are given by solutions from chapter 3.1 with the combination of MFH and PV. The two singular cases in Fig. 11 outside the curves are the SFH with $10 \mathrm{PV}$ modules without storage and the MFH with 1 ST module with $450 \mathrm{~m}^{3}$ NSTES (as of Figs. 4 a) and Fig. 9 a), respectively). The latter NSTES only reaches very low degrees of SCR of $<30 \%$ and when looking into the scaling by number of ST modules and storages size, it is obvious that the cost-efficiency of the solution is attributed to the small amount of ST. Again, this case is not a valid solution, since the produced solar thermal energy is too small.

The size of the NSTES has a strong negative correlation to the break-even, even more than the number of ST modules. The opposite conclusion is that a small ST system can potentially perform well, even better than a NSTES, using only the already present buffer storage (see Fig. 3), yet still with low SCR. An interesting comparison with a seemingly similar system, MFH-PVNSTES with 50-300 modules placed at the opposite corner of Fig. 11, provides insights in the difficulties of comparing PV and ST systems even when all other parameters are same, in contrast to only electrical storages [43] even so their technologies appear more 


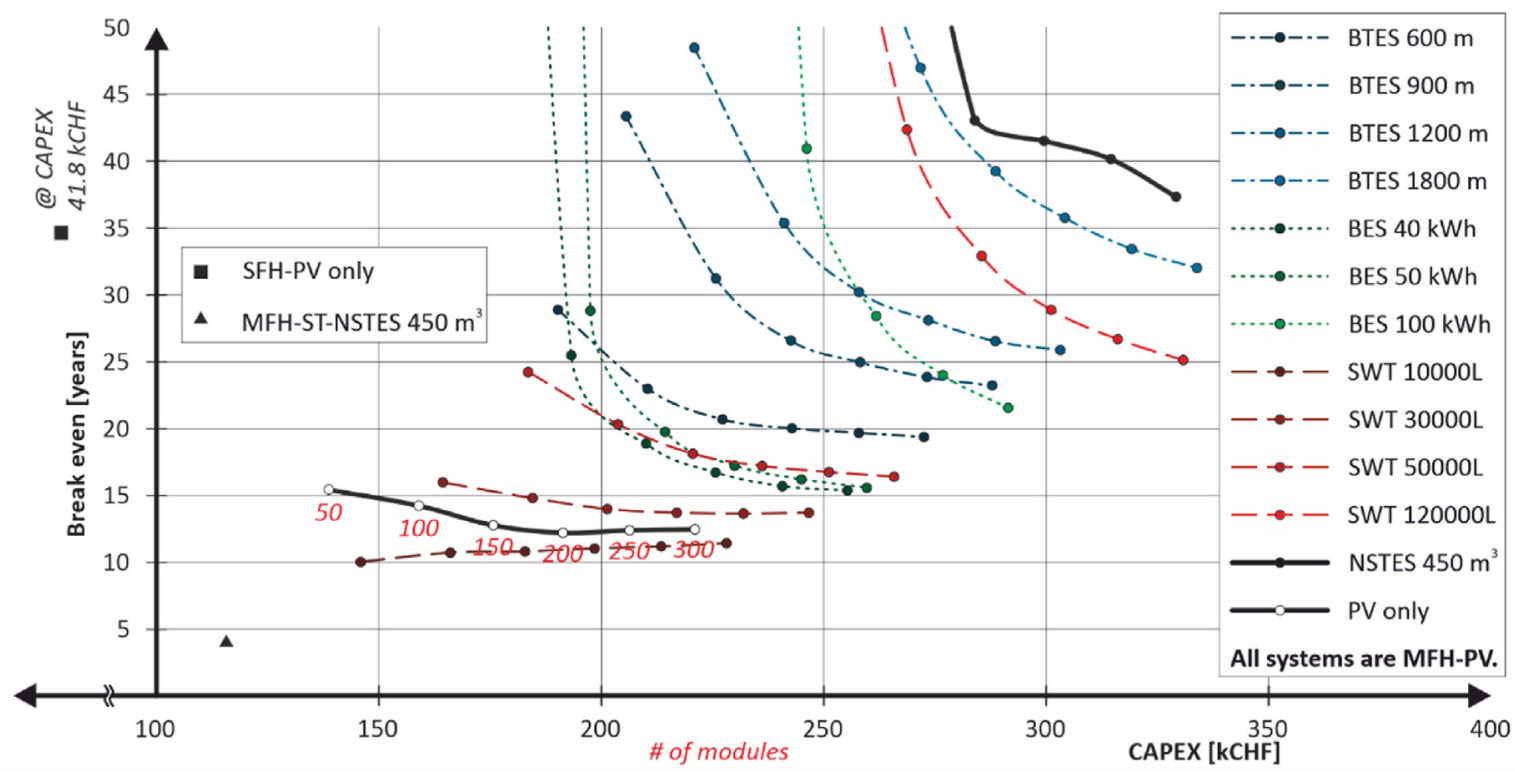

Fig. 11. Break-even for all systems $\leq 50$ years and rel. TCO $<1$. For all MFH-PV systems, data points represent \# of PV modules, ranging from 50 to 300 .

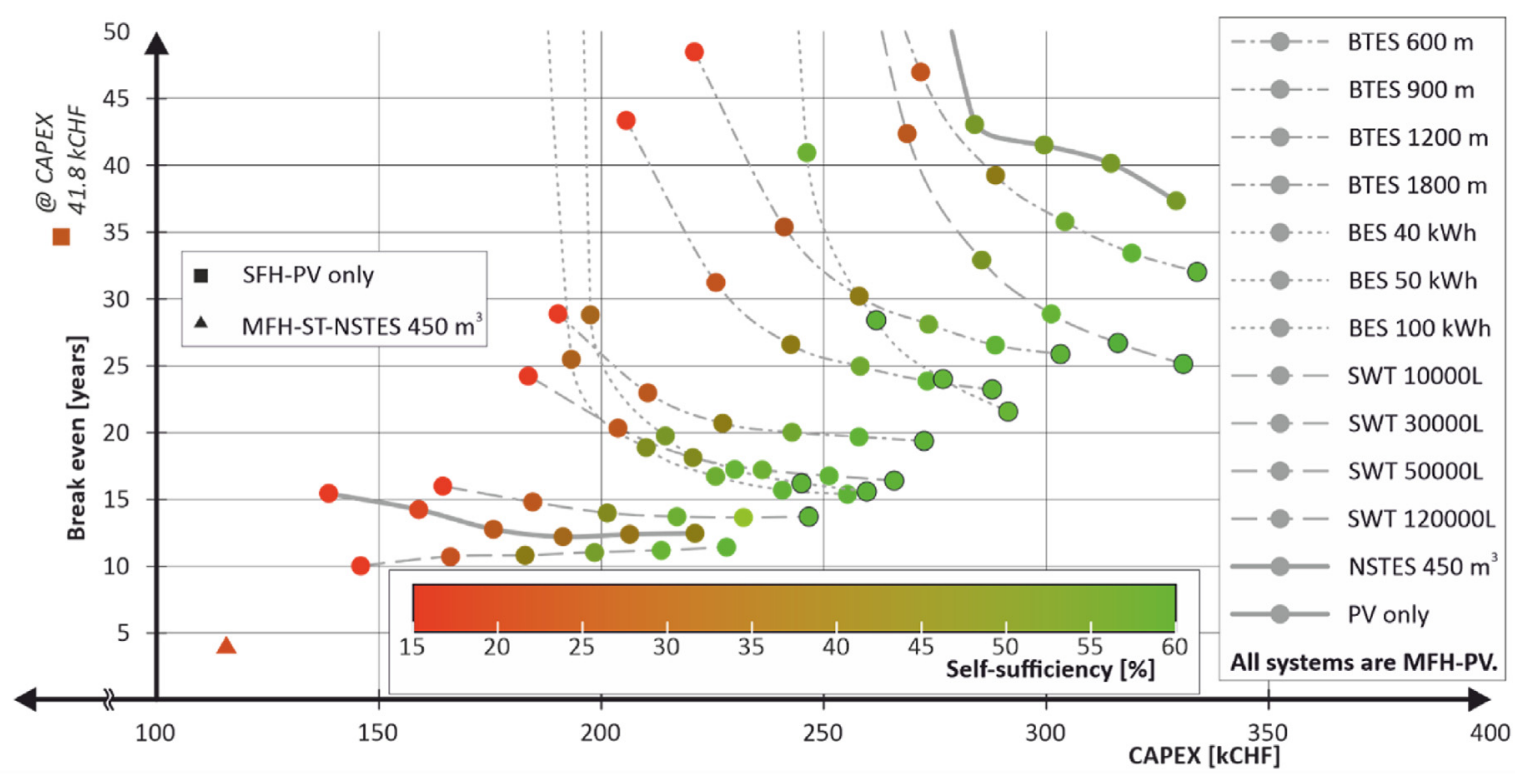

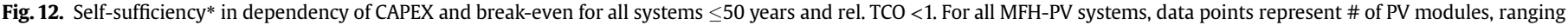

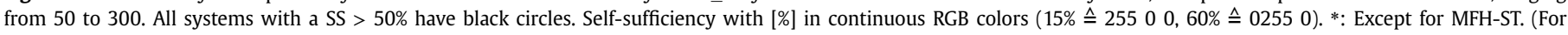
interpretation of the references to color in this figure legend, the reader is referred to the Web version of this article.)

heterogeneous. MFH-PV-NSTES (see Fig. 7 a) for reference) is not able to serve the load, is very costly due to the PV system, but positively correlates with the number of PV modules as they are creating a return of invest on their own. Again, we would like to stress the fact that the logic behind the assessment is in first priority a fair comparison based on equal energy performance as described in Fig. 1 a) and c). The given system solutions are not optimized for costs. TCOs are only ex post derived based on the solution.

To avoid a comparison of apples with oranges, the same set of curves is from Fig. 11 is now evaluated for degrees of self-sufficiency in Fig. 12 (full data is added in the supplementary material document, as Tables 9-12). The reason behind is the initial motivation to investigate the potential of storages to increase renewables for the thermal energy demand in the residential sector. Decentralized storages in conjunction with local PV or ST renewable energy production are resulting in greater self-sufficiency. Conversely, when retrofitting or constructing new houses, threshold levels for SS or SCR are provided by building standards and environmental labels established in response to political initiatives (e.g. the EU's Energy performance of buildings directive). The case MFH-PV only can reach SS values from 16\% (50 panels) to $36 \%$ (300 panels). With the aid of TES or BES, it is feasible to increase the SS to values beyond $50 \%$. Reaching $36 \%$ SS would only 
require 150 instead of 300 panels when adding a 10000 L SWT or a 600 m BTES.

It is worth mentioning, that in comparison, systems with storages on SFH-scale in general reach higher levels of SS systems on MFH-scale, yet due to the efficiency of scale the latter have an advantage in break-even. Finally, when comparing PV with ST systems, one has to look at SCR system data. The SCR System $_{\text {is by }}$ definition smaller than the SCR, while $S_{\text {System }}$ and SS both give an indication about which share from the total energy consumption can be attributed to the renewable energy collected on the rooftop. Even so, solar thermal energy is not used for the electricity demand, the $\mathrm{SCR}_{\text {System }}$ is able to reach very high values, on average above SSvalues on MFH-scale and on a par on SFH-scale. When considering the limitation of roof size, the results are even more supporting ST solutions.

\section{Summary and conclusions}

We performed a comparative assessment of 326 battery and thermal energy storage systems on single- and multi-family house (residential) scale for a representative site in Switzerland with an up-to-date building standard. All systems have been model and simulated in Polysun ${ }^{\mathrm{TM}}$. The evaluation has prioritized energy performance as a simulation goal and subsequently derived cost and energy performance figures. As a renewable energy source, solar thermal collectors have been contrasted with solar photovoltaic collectors, both paired with three different kinds of thermal storages (surface water tank, near-surface thermal energy storage, and borehole thermal energy storage) over a wide range of collector sizes. For solar PV, no storage option and battery storages have been added to the comparison. Since only market-ready technologies have been chosen, the selection is limited and not covering technologies of low and medium technology readiness levels. Quotation from suppliers have been gathered in order to have representative cost data.

The assessment focused (under the constraint of equal energy performance) on cost-related aspects, namely total cost of ownership, and its components capital expenses and operational expenses. Guiding questions of the assessment were the search for cost-efficient solutions with a reasonable financial payback period and the conjoined scaling factors for renewable energy input and storage size. The main conclusions are:

I. The system boundaries and the reference case are determining the limitations of the comparison. On a different site, with different thermal and electrical energy demand, the comparison would look different (disclaiming universal validity of the assessment). Furthermore, the kind of services provided have a strong influence on the performance; in our case we did consider domestic hot water and space heating, but not cooling.

II. In terms of energy flow and storage usage, the systems have strikingly unique optimal application areas. Battery energy storages are best used as hourly storages, whereas surface water tank are daily storages and borehole thermal energy storages have a dominating seasonal storage function. Some systems are lossy storages in the conventional sense, while others (borehole and near-surface thermal energy storage) directly use ambient heat as an additional source. In a similar vein, photovoltaics with heat pumps are a multiplier for energy harvesting. This makes the comparison between thermal and electrical storages (sectoral coupling to thermal sector) more difficult than only within the purpose of storing energy for the electricity sector.
III. Storages are in general not energy sources and they add to the investment costs. However, they help self-consuming the locally produced renewable energy and they can increase the use ambient energy from air and ground substantially. This reduces the amount of panels required, thus investment on the production side. Increased self-sufficiency reduces the amount of energy taken from the grid or from auxiliary sources, which reduces operational expenses.

IV. Investment into sustainable heating is usually driven by a targeted degree of autarky as in Fig. 12, given as selfsufficiency for photovoltaic systems and solar coverage ratio for solar thermal systems. When comparing among different technologies and solutions, equal energy performance and degrees of autarky are a primary design and optimization criteria, and the calculation of the total cost of ownership over a 50-year lifetime follows taking into account all applicable subsidies and local alterations of costs.

V. Under neutral conditions, only taking a moderate electrical feed-in tariff as return on investment, photovoltaic systems always outperform solar thermal systems in terms of relative total costs of ownership and therefore in reaching a financial break-even.

VI. Multi-family houses have a better efficiency of scale and yield in general a much better financial break-even than single-family houses.

VII. When targeting autarky, the conclusions V and VI are entirely contradicted. Solar thermal systems can easily reach solar coverage ratio (on system level, including electrical demand) above $50 \%$ when paired with a suitable thermal energy storage. Solar photovoltaic has better self-sufficiency on single-family house scale than on multi-family, while for solar thermal the results are juxtaposed.

VIII. Photovoltaics reach higher self-sufficiency with battery energy storage than with thermal energy storage on singlefamily house scale, however, none of the systems with storage was cost-efficient (see Fig. 11). On multi-family house scale, thermal storages were on par with batteries and potentially more cost-efficient.

Thermal energy storages did show an overall promising result in terms of energy performance. Further research in this field should consider the environmental benefits of thermal storage over battery storage. Additionally, emerging storage technologies in the realm of latent thermal energy storages and chemical energy storages could show gains in energy performance, when having an optimized exergy design.

\section{Credit author statement}

Matthias Berger: Conceptualization, Methodology, Validation, Writing - original draft, Visualization, Project administration, Benjamin Schroeteler, Helene Sperle: Software, Validation, Formal analysis, Investigation, Data curation, Writing - review \& editing, Patrizia Püntener, Tom Felder: Investigation, Data curation, Jörg Worlitschek: Resources, Supervision, Funding acquisition

\section{Declaration of competing interest}

The authors declare that they have no known competing financial interests or personal relationships that could have appeared to influence the work reported in this paper. 


\section{Acknowledgements}

This original research was conducted within the framework of the Swiss Competence Centers for Energy Research-Heat and Electricity Storage (SCCER-HAE) and was financially supported by the Commission for Technology and Innovation (CTI) Contract \#1155002545.

\section{Appendix A. Supplementary data}

Supplementary data to this article can be found online at https://doi.org/10.1016/j.energy.2021.122618.

\section{References}

[1] Taylor RA, Shoraka Y, Tehrani SSM, Nashed A. Thermal energy storage for buildings: a merit order review. Annu Rev Heat Transf. 2018;21.

[2] Gu W, Wang J, Lu S, Luo Z, Wu C. Optimal operation for integrated energy system considering thermal inertia of district heating network and buildings. Appl Energy 2017;199:234-46.

[3] Aste N, Angelotti A, Buzzetti M. The influence of the external walls thermal inertia on the energy performance of well insulated buildings. Energy Build 2009;41(11):1181-7.

[4] Verbeke S, Audenaert A. Thermal inertia in buildings: a review of impacts across climate and building use. Renew Sustain Energy Rev 2018;82:2300-18.

[5] Geidl M, Arnoux B, Plaisted T, Dufour S. A fully operational virtual energy storage network providing flexibility for the power system. In: Proceedings of the 12th IEA heat pump conference; 2017. p. 15-8. Rotterdam, The Netherlands.

[6] Facchinetti E, Sulzer S. General business model patterns for local energy management concepts. Front Energy Res 2016;4:7.

[7] Schuetz P, Gwerder D, Gasser L, Fischer LJ, Wellig B, Worlitschek J. Thermal storage improves flexibility of residential heating systems for smart grids. Proc. 12th IEA Heat Pump Conf 2017:1-9.

[8] Balint A, Kazmi H. Determinants of energy flexibility in residential hot water systems. Energy Build 2019;188-189:286-96.

[9] Battaglia M, Haberl R, Bamberger E, Haller M. Increased self-consumption and grid flexibility of PV and heat pump systems with thermal and electrical storage. Energy Procedia 2017;135:358-66.

[10] Swiss Federal Office of Energy. Schweizerische gesamtenergiestatistik 2017. Switzerland: Bern; 2018.

[11] Kemmler A, Spillman T. Ex-post-analyse. In: Der energieverbrauch der Privaten haushalte $2000-2018 ; 2019$.

[12] Berger M, Worlitschek J. A novel approach for estimating residential space heating demand. Energy 2018;159:294-301.

[13] Prognos AG. Die Energieperspektiven für die Schweiz bis 2050. Switzerland: Basel; 2012.

[14] Steinmann W-D, Bauer D, Jockenhöfer H, Johnson M. Pumped thermal energy storage (PTES) as smart sector-coupling technology for heat and electricity. Energy 2019;183:185-90.

[15] Brown T, Schlachtberger D, Kies A, Schramm S, Greiner M. Synergies of sector coupling and transmission reinforcement in a cost-optimised, highly renewable European energy system. Energy 2018;160:720-39.

[16] Gallo AB, Simões-Moreira JR, Costa HKM, Santos MM, Moutinho dos Santos E. Energy storage in the energy transition context: a technology review. Renew Sustain Energy Rev 2016;65:800-22.

[17] Zheng M, Meinrenken CJ, Lackner KS. Smart households: dispatch strategies and economic analysis of distributed energy storage for residential peak shaving. Appl Energy 2015;147:246-57.

[18] Lazard. Lazard's levelized cost of storage analysis - version 5.0. 2019.

[19] European Commission. A Clean Planet for all A European strategic long-term vision for a prosperous, modern, competitive and climate neutral economy.
Belgium: Brussels; 2018.

[20] European Parliament. European parliament resolution of 15 january 2020 on the European green deal. The Netherlands: Strasbourg; 2020.

[21] Stadler I, Sterner M. 2.3 - urban energy storage and sector coupling. Elsevier; 2018. p. 225-44. P. B. T.-U. E. T. (Second E. Droege.

[22] M. Gargiulo and B. Ó. Gallachóir, "Long-term energy models: principles, characteristics, focus, and limitations," WIREs Energy Environ, vol. 2, no. 2, pp. 158-177, Mar. 2013.

[23] Berger M, Worlitschek J. The influence of climate trends on heating and cooling demand. "forthcoming; 2018.

[24] Allegrini J, Orehounig K, Mavromatidis G, Ruesch F, Dorer V, Evins R. A review of modelling approaches and tools for the simulation of district-scale energy systems. Renew Sustain Energy Rev 2015;52:1391-404.

[25] Krippendorff K. Information theory: structural models for qualitative data, vol. 62. Sage; 1986.

[26] Panos E, Kannan R. In: Giannakidis G, Karlsson K, Labriet M, Gallachóir Bó, editors. Challenges and opportunities for the Swiss energy system in meeting stringent climate mitigation targets BT - limiting global warming to well below $2{ }^{\circ} \mathrm{C}$ : energy system modelling and policy development. Cham: Springer International Publishing; 2018. p. 155-72.

[27] Kannan R, Turton H. Documentation on the development of the Swiss TIMES electricity model (STEM-E). " Paul Scherrer Institute (PSI); 2011.

[28] Schulze M, Friedrich L, Gautschi M. Modeling and optimization of renewables: applying the energy hub approach. In: "Sustainable energy technologies, 2008. IEEE International Conference on; 2008. p. 83-8. ICSET 2008.

[29] Berger M. Validierung des Energy Hub Konzepts mittels einer Fallstudie in Baden-Dättwil. " ETH Zurich; 2011.

[30] M. Erb, P. Hubacher, and M. Ehrbar, "Feldanalyse von Wärmepumpenanlagen-fawa 1996-2003," 2004.

[31] Fraga C, Hollmuller P, Schneider S, Lachal B. Heat pump systems for multifamily buildings: potential and constraints of several heat sources for diverse building demands. Appl Energy 2018;225:1033-53.

[32] Lai CS, McCulloch MD. Levelized cost of electricity for solar photovoltaic and electrical energy storage. Appl Energy 2017;190:191-203.

[33] Lacoste B, Wolf A. A. [Vela S. A. G. Witzig winterthur (Switzerland)], and A. [Envergate G. Maerklin horn (Switzerland)]. In: Polysun. PV, wind and powerheat-cogeneration in one design tool; 2010.

[34] Brönner P, Witzig A, Pfeiffer M, Bornatico R. Polysun Grundlagen: Übersicht über Numerik und physikalische Modelle,. In: 21. Symposium thermische solarenergie: 11.-13. Mai 2011. Kloster Banz, Bad Staffelstein; 2011. p. 443-8.

[35] SIA. Norm 380/1: heizwärmebedarf," Schweizerischer Ingenieur und Architektenverein. Zurich; 2016. p. 60.

[36] Konferenz Kantonaler Energiedirektoren. Mustervorschriften der Kantone im Energiebereich (MuKEn) 2014 Edition. Switzerland: Bern; 2014.

[37] Hoffmann C, Geissler A, Carisch L. Warum stimmt das nie?. Fragen beim Einsatz der SIA 380/1 als Prognoseinstrument bei Bestandsgebäuden (Wohnen),. In: In 19. Status-Seminar «Forschen für den Bau im Kontext von Energie und Umwelt»; 2016.

[38] Calì D, Osterhage T, Streblow R, Müller D. Energy performance gap in refurbished German dwellings: lesson learned from a field test. Energy Build 2016;127:1146-58.

[39] Zhang Y, Lin K, Zhang Q, Di H. Ideal thermophysical properties for free-cooling (or heating) buildings with constant thermal physical property material. Energy Build 2006;38(10):1164-70.

[40] Berger M, Waser R. Advanced latent thermal energy storage for space cooling in the tropics. In: 2019 IEEE PES GTD grand international conference and exposition asia. GTD Asia); 2019. p. 842-7.

[41] Streicher KN, Parra D, Buerer MC, Patel MK. Techno-economic potential of large-scale energy retrofit in the Swiss residential building stock. Energy Procedia 2017;122(September):121-6.

[42] Streicher KN, Padey P, Parra D, Bürer MC, Schneider S, Patel MK. Analysis of space heating demand in the Swiss residential building stock: element-based bottom-up model of archetype buildings. Energy Build 2019;184:300-22.

[43] Abdon A, Zhang X, Parra D, Patel MK, Bauer C, Worlitschek J. Techno-economic and environmental assessment of stationary electricity storage technologies for different time scales. Energy 2017;139:1173-87. 